\title{
Non-canonical heterogeneous cellular distribution and co-localization of CaMKII $\alpha$ and CaMKII $\beta$ in the spinal superficial dorsal horn
}

\author{
Max Larsson ${ }^{1}$ (D)
}

Received: 3 February 2017/ Accepted: 8 November 2017/Published online: 18 November 2017

(C) The Author(s) 2017. This article is an open access publication

\begin{abstract}
Ca}^{2+} /$ calmodulin-dependent protein kinase II (CaMKII) is a key enzyme in long-term plasticity in many neurons, including in the nociceptive circuitry of the spinal dorsal horn. However, although the role of CaMKII heterooligomers in neuronal plasticity is isoform-dependent, the distribution and co-localization of CaMKII isoforms in the dorsal horn have not been comprehensively investigated. Here, quantitative immunofluorescence analysis was used to examine the distribution of the two major neuronal CaMKII isoforms, $\alpha$ and $\beta$, in laminae I-III of the rat dorsal horn, with reference to inhibitory interneurons and neuronal populations defined by expression of parvalbumin, calretinin, and calbindin D28k. Unexpectedly, all or nearly all inhibitory and excitatory neurons showed both CaMKII $\alpha$ and CaMKII $\beta$ immunoreactivity, although at highly variable levels. Lamina III neurons showed less CaMKII $\alpha$ immunoreactivity than laminae I-II neurons. Whereas CaMKII $\alpha$ immunoreactivity was found at nearly similar levels in inhibitory and excitatory neurons, CaMKII $\beta$ generally showed considerably lower immunoreactivity in inhibitory neurons. Distinct populations of inhibitory calretinin neurons and excitatory parvalbumin neurons exhibited high CaMKII $\alpha$-to-CaMKII $\beta$ immunoreactivity ratios. CaMKII $\alpha$ and $\mathrm{CaMKII} \beta$ immunoreactivity showed positive correlation at $\mathrm{GluA} 2^{+}$puncta in pepsintreated tissue. These results suggest that, unlike the forebrain, the dorsal horn is characterized by similar expression of CaMKII $\alpha$ in excitatory and inhibitory neurons, whereas
\end{abstract}

Max Larsson

max.larsson@liu.se

1 Department of Clinical and Experimental Medicine, Division of Neurobiology, Linköping University, SE-581 85 Linköping, Sweden
CaMKII $\beta$ is less expressed in inhibitory neurons. Moreover, CaMKII isoform expression varies considerably within and between neuronal populations defined by laminar location, calcium-binding protein expression, and transmitter phenotype, suggesting differences in CaMKII function both between and within neuronal populations in the superficial dorsal horn.

Keywords Pain - Central sensitization - Spinal cord . Pax2 - GABA

\section{Introduction}

$\mathrm{Ca}^{2+} /$ calmodulin-dependent protein kinase II (CaMKII) is well established as a pivotal enzyme in neuronal plasticity (Hell 2014; Lisman et al. 2012; Coultrap and Bayer 2012). CaMKII exists as heterooligomers of $\alpha, \beta, \gamma$, and $\delta$ isoforms, of which $\alpha$ and $\beta$ are essentially restricted to neurons, whereas $\gamma$ and $\delta$ are more widely expressed. Most studies on the role of CaMKII in neuronal plasticity have focused on the $\alpha$ subunit or used tools that do not differentiate between different isoforms. For instance, autophosphorylation of CaMKII $\alpha$ at T286 has been shown to be critical for learning and long-term potentiation (LTP) at some glutamatergic synapses (Hell 2014; Lisman et al. 2012). Nevertheless, major functional differences between CaMKII $\alpha$ and CaMKII $\beta$ have been identified (Liu and Murray 2012; Hell 2014). The $\beta$ isoform binds F-actin and targets $\alpha / \beta$ heteromers to dendritic spines (e.g., Borgesius et al. 2011; Shen et al. 1998); this binding is abolished by $\mathrm{Ca}^{2+} /$ calmodulin or autophosphorylation, allowing the holoenzyme to translocate to the postsynaptic density in an activity-dependent manner (Shen and Meyer 1999). Moreover, CaMKII $\beta$ is more sensitive than CaMKII $\alpha$ to 
$\mathrm{Ca}^{2+} /$ calmodulin and $\mathrm{Ca}^{2+}$ spike frequency, whereas heteromers show intermediate sensitivity (Brocke et al. 1999; De Koninck and Schulman 1998). The subunit composition of CaMKII oligomers in a cell is stochastically determined based on the relative expression of each isoform (Shen et al. 1998). Thus, differential expression patterns of CaMKII isoforms confer cell-wide differences in functional characteristics of the enzyme between neuronal populations. Notably, with some exceptions such as cerebellar Purkinje cells, CaMKII $\alpha$ has been reported to be essentially restricted to excitatory neurons in the rodent CNS (Benson et al. 1992; Sík et al. 1998). The cell-specific distribution of CaMKII $\beta$ is less characterized, although at least some populations of inhibitory neuron express this isoform (Ochiishi et al. 1994; Burgin et al. 1990).

Similar to its role in the brain, CaMKII has been strongly implicated in spinal sensory plasticity, including primary afferent long-term potentiation, hyperalgesia, and sensitization of dorsal horn neurons to sensory stimuli (e.g., Fang et al. 2002; Yang et al. 2004; Zeitz et al. 2004; Larsson and Broman 2006; Larsson 2009; Larsson and Broman 2011). However, the role of CaMKII in spinal nociceptive plasticity remains enigmatic and, in some instances, appears counter to established model mechanisms of CaMKII-mediated neuronal plasticity. For instance, some types of spinal plasticity and hyperalgesia appear to not require CaMKII activation, or autophosphorylation of CaMKII $\alpha$ (Jones and Sorkin 2005; Zeitz et al. 2004). Furthermore, we have observed, in the capsaicin model of hyperalgesia, a curious downregulation of CaMKII and autophosphorylated CaMKII in the postsynaptic density of non-peptidergic $\mathrm{C}$ fiber synapses; this downregulation is concomitant with upregulation of GluA1containing $\alpha$-amino-3-hydroxy-5-methyl-4-isoxazole propionic acid (AMPA) receptors at the same synapses (Larsson and Broman 2006, 2008). It is possible that this discordance with respect to the established model of CaMKII-mediated synaptic plasticity is attributed to differential isoform expression and function of CaMKII between dorsal horn neurons. As a first step to investigate this issue, the present study was devoted to examine the distribution and co-localization of CaMKII $\alpha$ and CaMKII $\beta$ in certain excitatory and inhibitory neuronal populations in the superficial dorsal horn.

\section{Materials and methods}

\section{Tissue preparation}

Adult male Sprague-Dawley rats were anaesthetized with sodium pentobarbital $(60 \mathrm{mg}$, i.p.) and rapidly perfused transcardially with phosphate-buffered saline (PBS,
$300 \mathrm{mOsm}, \mathrm{pH}$ 7.4) followed by PBS containing 4\% paraformaldehyde $(0.5-1 \mathrm{~L}, 20 \mathrm{~min})$. After perfusion, the lumbar spinal cord (L3-L5) was removed and placed in $30 \%$ sucrose in PBS. In addition, spinal cord tissue perfusion fixed with $4 \%$ paraformaldehyde was obtained from 4-week-old mice deficient in CaMKII $\alpha\left(\mathrm{Camk2a^{-/ }}\right.$ ) (Elgersma et al. 2002) or CaMKII $\beta$ (Camk2 $\left.b^{-1-}\right)($ Gao et al. 2014) and corresponding wild-type mice (a gift from Y. Elgersma). Transverse spinal cord sections were cut on a freezing microtome at a thickness of $40 \mu \mathrm{m}$ and stored at $-20{ }^{\circ} \mathrm{C}$ in cryoprotectant $(30 \%$ glycerol and $30 \%$ ethylene glycol in $0.1 \mathrm{M}$ phosphate buffer, $\mathrm{pH}$ 7.4) until use. All animal experiments were approved by the local Research Animal Care and Use Committee.

\section{Antibodies}

Primary antibodies used in this study are specified in Table 1. The mouse anti-CaMKII $\alpha$ clone 6G9 (Erondu and Kennedy 1985) has been widely used and its selectivity for CaMKII $\alpha$ is well characterized. For instance, very little staining was observed in the early postnatal rat cerebral cortex (Ding et al. 2013), where CaMKII $\beta$ but not CaM$\mathrm{KII} \alpha$ is expressed at considerable levels (Burgin et al. 1990). The mouse anti-CaMKII $\beta$ antibody produced no staining in the brain of Camk2 $b^{-1-}$ mice (Bachstetter et al. 2014; van Woerden et al. 2009). The guinea pig anti-NeuN antibody recognizes the NeuN/Fox 3 protein and produced very similar pattern of staining in the rat spinal cord as the original NeuN antibody (Todd et al. 1998; Larsson 2017). Similarly, guinea pig antibodies directed towards calbindin D28k, calretinin, and parvalbumin yielded immunolabeling patterns in the rat spinal cord and brain consistent with the previous reports (e.g., Antal et al. 1991; Ren and Ruda 1994; Antal et al. 1990). The Pax2 antibody used here has been shown to specifically and selectively label essentially all GABAergic neurons in the spinal dorsal horn of adult rats (Larsson 2017). The GluA2 antibody used in combination with pepsin-mediated antigen retrieval has been shown to label synaptic GluA2 (Polgár et al. 2008).

\section{Immunofluorescence}

As the CaMKII $\alpha$ and CaMKII $\beta$, mouse antibodies were of different subclasses $\left(\operatorname{IgG}_{1}\right.$ and $\operatorname{IgG}_{2 b}$, respectively), it was possible to use subclass-specific secondary antibodies for simultaneous detection of the isoform on the same spinal cord sections. Moreover, in most cases, quadruple immunofluorescent labeling was performed using the CaMKII antibodies in combination with rabbit anti-Pax2 and a guinea pig antibody for NeuN or a calcium-binding protein. In some cases, mouse tissue sections were subjected to heat-induced antigen retrieval using a citrate 
Table 1 Primary antibodies used

\begin{tabular}{llllllll}
\hline Antigen & Host, isotype & Clone & Immunogen & Supplier & Cat\# & Lot\# & Concentration \\
\hline Calbindin D28k & Guinea pig & Polyclonal & Human aa 3-251 & Synaptic Systems & 214004 & $214004 / 5$ & $1: 250$ \\
Calretinin & Guinea pig & Polyclonal & Mouse protein & Synaptic Systems & 214104 & $214104 / 2$ & $1: 500$ \\
CaMKII $\alpha$ & Mouse, IgG & 6G9 & Rat protein & Millipore & MAB8699 & 21020859 & $1: 1000$ \\
CaMKII $\alpha$ & Mouse, IgG $_{1}$ & 6G9 & Rat protein & Thermo Fisher & MA1-048 & QI222632 & $1: 1000$ \\
CaMKII $\beta$ & Mouse, IgG $_{2 b}$ & CB-beta-1 & Rat protein & LifeSpan & LS-B5767 & 60012,69070 & $1: 200$ \\
GluA2 & Mouse, IgG $_{2 \mathrm{a}}$ & 6C4 & N-terminal & Millipore & MAB397 & 2049209 & $1: 250$ \\
Iba1 & Rabbit & EPR16588 & Mouse aa 100-147 & Abcam & Ab178846 & GR249899 \\
NeuN & Guinea pig & Polyclonal & Mouse aa 1-97 & Synaptic Systems & 266 004 & $266004 / 5$ & $1: 250$ \\
Parvalbumin & Guinea pig & Polyclonal & Rat protein & Synaptic Systems & 195 004 & $195004 / 9$ & $1: 500$ \\
Pax2 & Rabbit & Polyclonal & Human aa 268-332 & Atlas Antibodies & HPA047704 & R44792 & $1: 50-1: 100$ \\
\hline
\end{tabular}

buffer (pH 6.1; DAKO, Glostrup, Denmark) at $97{ }^{\circ} \mathrm{C}$ for 20 min. Briefly, lumbar spinal cord sections were incubated in PBS containing 3\% normal goat serum, $0.5 \%$ bovine serum albumin and $0.5 \%$ Triton X-100 (blocking solution) and in primary antibodies diluted in blocking solution (see Table 1) overnight or for 2 days (for calbindin and calretinin immunofluorescence, to allow antibody penetration throughout the section) at room temperature. After washing in PBS, the sections were incubated in goat anti-rabbit Alexa Fluor 405 (1:250) or donkey anti-rabbit Brilliant Violet 421 (1:100), goat antimouse $\mathrm{IgG}_{2 \mathrm{~b}}$ Alexa Fluor 488 (1:500), goat anti-mouse $\mathrm{IgG}_{1}$ Alexa Fluor 568 (1:500), and goat anti-guinea pig Alexa Fluor 647 (1:500) for 2-4 h. Sections were mounted on glass slides and coverslipped using Prolong Gold (Life Technologies). In one set of experiments, CaMKII $\alpha$ and CaMKII $\beta$ antibodies were mixed with biotinylated isolectin B4 (1:500; Life Technologies), which was detected using streptavidin-Alexa Fluor 405 (1:250; Life Technologies). In one experiment, to enable labeling of CaMKII in the postsynaptic density, rat tissue sections were subject to antigen retrieval by incubation in pepsin (DAKO; $1 \mathrm{mg} /$ $\mathrm{mL}$ in $10 \mathrm{mM} \mathrm{HCl}$ ) at $37{ }^{\circ} \mathrm{C}$ for $7 \mathrm{~min}$ prior to the immunofluorescence procedure (Larsson et al. 2013; Nagy et al. 2004; Polgár et al. 2008; Watanabe et al. 1998). In this case, anti-GluA2 was used as an excitatory synaptic marker. To test the specificity of the subclass-specific antimouse secondary antibodies, sections were incubated with either CaMKII $\alpha$ or CaMKII $\beta$ antibody and subsequently in both goat anti-mouse $\operatorname{IgG}_{2 b}$ Alexa Fluor 488 and goat antimouse $\mathrm{IgG}_{1}$ Alexa Fluor 568; no cross-reactivity for the other IgG subclass was evident for either secondary antibody (see also Manning et al. 2012). In one NeuN/Pax2 double labeling experiment, goat anti-rabbit Alexa Fluor 488 (1:500) and goat anti-guinea pig Alexa Fluor 568 (1:500) were used for secondary detection. All secondary antibodies were from Life Technologies, except donkey anti-rabbit Brilliant Violet 421, which was from BioLegend (San Diego, CA, USA).

\section{Microscopy}

To compare the laminar distribution of CaMKII $\alpha$ and CaMKII $\beta$ immunolabeling, an Olympus BX51 microscope was used to acquire epifluorescence and dark field micrographs with a $10 \times / 0.3$ objective. For all other microscopy, a Zeiss LSM700 confocal microscope was used. For quantitative analysis, $\mathrm{z}$-stacks of optical sections at $1 \mu \mathrm{m}$ separation were acquired of the entire superficial dorsal horn (laminae I-III) throughout the thickness of the tissue section using the automatic tile scan function with a $40 \times 1$ 1.3 oil immersion objective. To limit bleaching and acquisition time, pixel dwell time and frame averaging were set to minimal values, while pixel width was set to $96 \mathrm{~nm}$. For each fluorescence channel, the same gain and offset were used for all sections from an animal in a given experiment. In the case of the tissue treated with pepsin to reveal synaptic proteins, a $63 \times / 1.4$ oil immersion objective was used to acquire single optical slices of $400 \mu \mathrm{m}^{2}$ regions (pixel size $40 \mathrm{~nm}$ ) of laminae I-III at the surface of the section, where GluA2 immunopositive puncta were evident. Micrographs for publication were acquired using the $63 \times / 1.4$ oil immersion objective, or, for the isolectin B4 staining experiment, as a tile scan with the $40 \times / 1.3$ oil immersion objective. Some publication micrographs were deconvolved using the Huygens software (Scientific Volume Imaging), as noted.

\section{Quantitative analysis}

For each quadruple immunofluorescence experiment, tissue sections from two or three animals were used for quantitative analysis. The z-stack of each tissue section was opened in ImageJ and each lamina scanned for cells 
immunopositive for the marker of interest, while the CaMKII $\alpha /$ CaMKII $\beta$ channels were switched off. For the purpose of this study, lamina II was divided into an outer (IIo) and an inner (IIi) half of equal thickness. Care was taken to only analyze the portion of the z-stack in which the optical sections had similar overall intensities. In all experiments, immunolabeling for each antibody showed homogeneous penetration throughout the section, except occasionally at the section surface. After selection of a profile, the optical section with the largest cross section through the profile and with the most distinct profile boundaries (relative to surrounding neuropil and the profile's nucleus) as assessed in the marker or CaMKII $\alpha$ / CaMKII $\beta$ channels was analyzed by outlining the profile

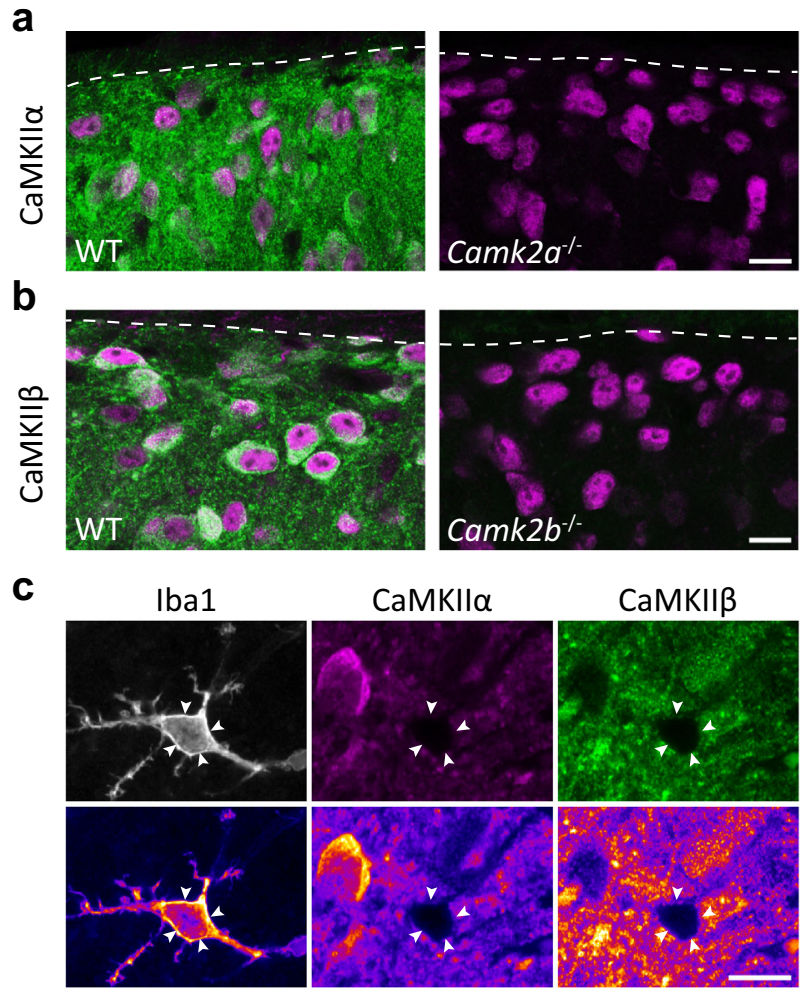

Fig. 1 Validation of CaMKII $\alpha$ and CaMKII $\beta$ antibodies for immunofluorescence in the spinal dorsal horn. a CaMKII $\alpha$ (green) and NeuN (magenta) immunofluorescence in the superficial dorsal horn of wild-type and CaMKII $\alpha^{-1-}$ mice. CaMKII $\alpha$ immunolabeling was essentially absent in CaMKII $\alpha$-deficient mice. b CaMKII $\beta$ (green) and NeuN (magenta) immunofluorescence in the superficial dorsal horn of wild-type and CaMKII $\beta^{-1-}$ mice. CaMKII $\beta$ immunolabeling was essentially absent from CaMKII $\beta^{-1-}$ mice, apart from a weak staining of myelin. Dashed lines in $\mathbf{a}$ and $\mathbf{b}$ indicate the dorsal border of lamina I. Micrographs are single optical sections obtained using a $63 \times / 1.4$ objective. Scale bar, $10 \mu \mathrm{m}$, valid for a and b. c Example of an $\mathrm{Iba1}^{+}$microglial cell in lamina II of the rat spinal cord devoid of both CaMKII $\alpha$ and CaMKII $\beta$ immunoreactivity. Bottom panels are pseudocolored to better visualize weak immunolabeling. Arrowheads indicate the microglial cell body. Micrographs are singe optical sections obtained with a $63 \times / 1.4$ objective. Scale bar, $10 \mu \mathrm{m}$ border and measuring the mean intensity of the resulting region of interest in all channels. Cells where no distinct cytoplasm/nucleus boundary could be found in any optical section were discarded, as were cells for which the largest or most distinct cross section was found at either extreme optical section of the usable portion of the z-stack. To normalize channel intensities across sections and experiments, in each analyzed section, the mean channel intensities over laminae I-III were measured in one representative optical section at the center of the tissue section, and the channel intensities of each profile in that section were normalized to these average intensities. Normalized CaMKII $\alpha$ and CaMKII $\beta$ immunofluorescence intensities were very similar between sections and animals both with respect to overall immunolabeling patterns and absolute values, and results were, therefore, pooled for each experiment.

For analysis of NeuN/Pax $2 / \mathrm{CaMKII} \alpha / \mathrm{CaMKII} \beta$ labeled sections, in two animals, $50 \mathrm{NeuN-immunopositive} \mathrm{cells}$ were initially selected in each lamina of each animal to estimate the proportion of Pax 2 immunopositive neurons. Subsequently, additional $\mathrm{NeuN}^{+}$profiles were selected based on Pax2 immunopositivity to yield $50 \mathrm{NeuN}^{+} / \mathrm{Pax} 2^{-}$
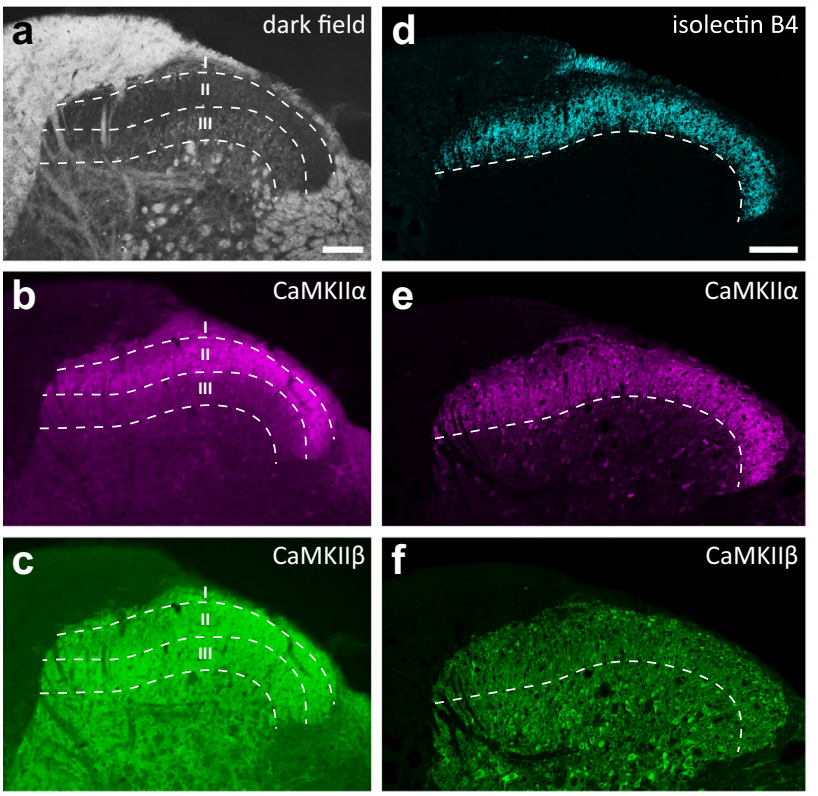

Fig. 2 Laminar distribution of CaMKII $\alpha$-LI and CaMKII $\beta$-LI in the lumbar dorsal horn. Dark field microscopy (a) combined with epifluorescence of CaMKII $\alpha$-LI (b) and CaMKII $\beta$-LI (c) shows enrichment of CaMKII $\alpha$-LI but not CaMKII $\beta$-LI in laminae I-II. Borders between laminae I-III are indicated by dashed lines. Confocal microscopy of isolectin B4 binding (d) and CaMKII $\alpha-\mathrm{LI}$ (e) and CaMKII $\beta$-LI (f) imaged using a $\times 40$ objective and tile scan. Note the correspondence between the ventral limit of isolectin B4 binding and the ventral aspect of the enrichment CaMKII $\alpha$-LI in lamina II (indicated by dashed lines). Scale bars in a and $\mathbf{d}$ are $100 \mu \mathrm{m}$, valid for $\mathbf{a}-\mathbf{c}$ and $\mathbf{d}-\mathbf{f}$, respectively 

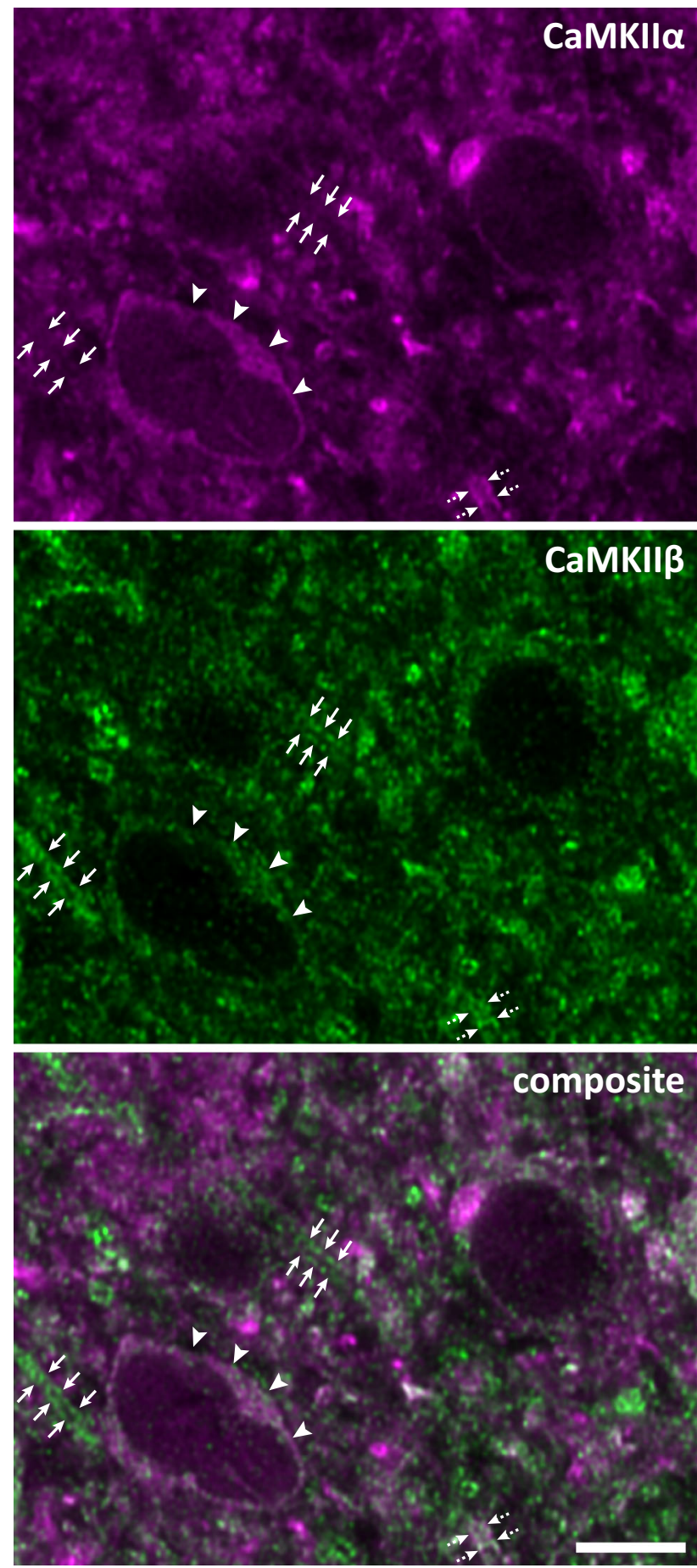

and $50 \mathrm{NeuN}^{+} / \mathrm{Pax}^{+}$cells in each lamina and animal. Cells were selected in a random manner without reference to CaMKII $\alpha$ or CaMKII $\beta$ immunolabeling; care was taken to select cells throughout the mediolateral and dorsoventral extent of each lamina. Moreover, in this experiment, ependymal cells (30 per animal) were outlined and their CaMKII $\alpha$ and CaMKII $\beta$ immunolabeling intensities measured. In an additional experiment, $\mathrm{NeuN}^{+}$neurons in the
४Fig. 3 CaMKII $\alpha$-LI and CaMKII $\beta$-LI in neuropil and cell bodies in lamina II. Shown is a high-magnification view of a portion of lamina IIi, exemplifying the differential patterns of immunolabeling for CaMKII $\alpha$ and CaMKII $\beta$ in the superficial dorsal horn. The micrograph is a single deconvolved optical section. CaMKII $\alpha$-LI is relatively diffused and concentrated in the somatic cytoplasm and as larger puncta in the neuropil, whereas CaMKII $\beta$-LI is more finegrained, both in somata and neuropil. Arrowheads indicate a neuron which shows moderate cytoplasmic staining for both CaMKII $\alpha$ and CaMKII $\beta$. Note, however, the very weak CaMKII $\beta$-LI in the nucleus. Arrows indicate two processes with strong CaMKII $\beta$-LI but weak CaMKII $\alpha$-LI, whereas dashed arrows indicate a process segment exhibiting strong CaMKII $\alpha$-LI as well as CaMKII $\beta$-LI. Scale bar is $5 \mu \mathrm{m}$

superficial dorsal horn of five sections from one animal were scored from 0 to 4 with respect to CaMKII $\alpha$ and CaMKII $\beta$ immunoreactivity (where 0 represents essentially no immunoreactivity), whereas Pax2 immunoreactivity was subsequently scored as positive or negative.

In the case of parvalbumin/Pax $2 / \mathrm{CaMKII} \alpha / \mathrm{CaMKII} \beta$ labeling, all tissue sections were scanned for parvalbumin immunopositive cells with all other channels switched off. All parvalbumin cells in laminae IIi-III which fit the general criteria as outlined above were included in the analysis. In addition, to assess cytoplasmic versus nuclear labeling in parvalbumin cells, the nucleus of each parvalbumin cell was outlined (in the CaMKII $\alpha$ or CaMKII $\beta$ channel), and the area and integrated pixel density of each channel measured in the soma and nucleus. Mean cytoplasmic intensity $\bar{d}_{\text {cytoplasm }}$ was calculated using the following equation:

$\bar{d}_{\text {cytoplasm }}=\frac{D_{\text {soma }}-D_{\text {nucleus }}}{A_{\text {soma }}-A_{\text {nucleus }}}$,

where $D_{\text {soma }}$ and $D_{\text {nucleus }}$ are the integrated density of the soma and nucleus, respectively, and $A_{\text {soma }}$ and $A_{\text {nucleus }}$ are the areas of these compartments.

In calretinin/Pax $2 / \mathrm{CaMKII} \alpha / \mathrm{CaMKII} \beta$ labeled sections, analysis was conducted in laminae I-II, where all calretinin immunolabeled cells that fitted the general criteria were included in the analysis. In sections immunolabeled for calbindin D28k/Pax $2 / \mathrm{CaMKII} \alpha / \mathrm{CaMKII} \beta$, the initial scanning suggested that few calbindin D28k cells expressed Pax2. Therefore, the quantitative analysis was restricted to Pax $2^{-}$cells. One hundred calbindin $\mathrm{D} 28 \mathrm{k}^{+} / \mathrm{Pax} 2^{-}$ cells were randomly selected for analysis in each lamina and animal.

For analysis of synaptic CaMKII, 200 GluA2 immunopositive puncta were randomly selected in each lamina in micrographs of pepsin-treated tissue. The puncta were outlined and the intensities of CaMKII $\alpha$ and CaMKII $\beta$ immunofluorescence measured. 
a
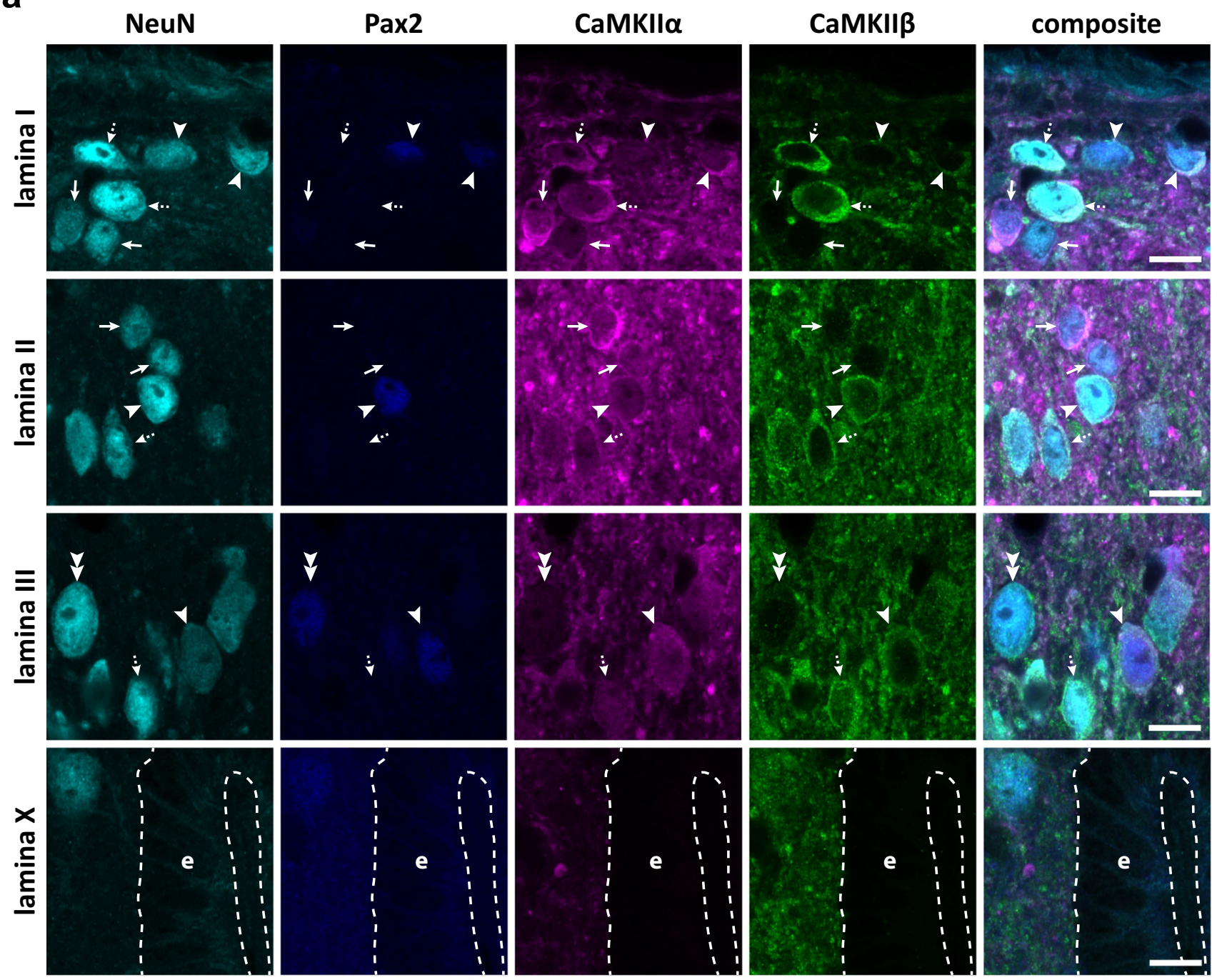

b

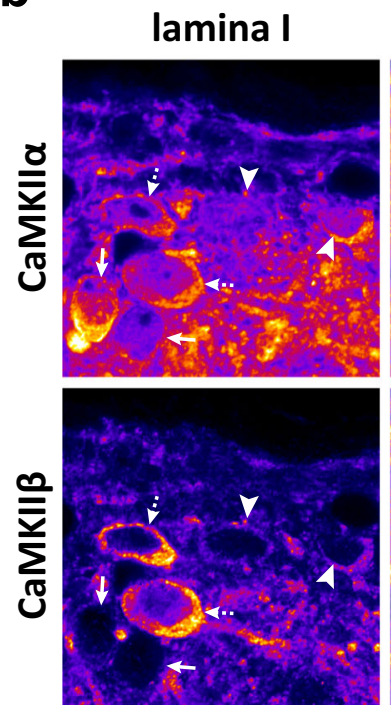

lamina II
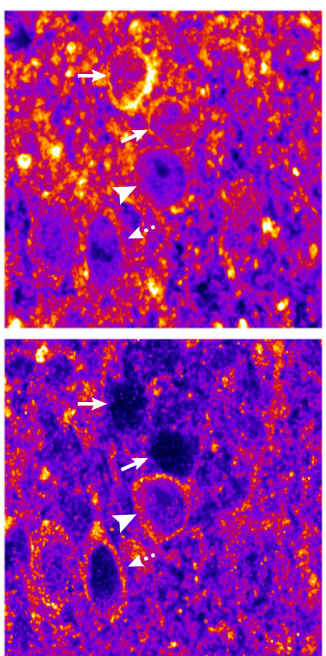

lamina III
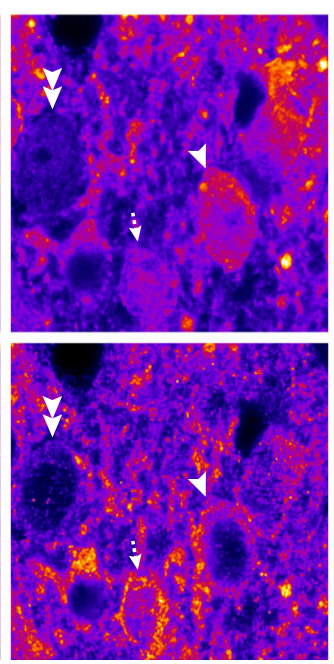

lamina $\mathrm{X}$

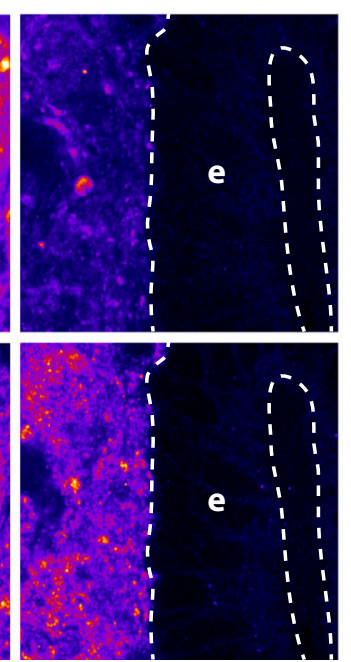


4Fig. 4 CaMKII $\alpha$-LI and CaMKII $\beta$-LI in excitatory and inhibitory dorsal horn neurons. a Examples of NeuN immunolabeled cells in laminae I-III that differentially label for Pax2, CaMKII $\alpha$ and CaMKII $\beta$. Arrowheads indicate $\mathrm{Pax}^{+}$cells with varying $\mathrm{CaM}-$ $\mathrm{KIII} \alpha$-LI and CaMKII $\beta$-LI. Arrows indicate Pax $2^{-}$cells with strong CaMKII $\alpha$-LI and weak CaMKII $\beta$-LI, while dashed arrows indicate Pax $2^{-}$cells with both strong CaMKII $\alpha-$ LI and strong CaMKII $\beta$-LI. Double arrowhead indicates a $\mathrm{Pax} 2^{+}$cell that shows both weak CaMKII $\alpha$-LI and weak CaMKII $\beta$-LI. Note the variable nuclear $\mathrm{CaMKII} \alpha$-LI and consistently weak nuclear CaMKII $\beta$-LI. Also note the substantial CaMKII $\alpha$-LI also in some lamina III cells. Shown is also a micrograph of lamina $\mathrm{X}$ and ependymal cells (e) lining the central canal. Dashed lines indicate basal and apical borders of the ependymal cell layer. Note the very weak CaMKII $\alpha$-LI and CaMKII $\beta$-LI over ependymal cells. b Same panels of CaMKII $\alpha$-LI and CaMKII $\beta$-LI as shown in a, but using a false-color look-up table to increase the visibility of weak immunofluorescence. Note that cells with weak CaMKII $\alpha$-LI or CaMKII $\beta$-LI, nevertheless, show substantially stronger immunolabeling as compared to the ependymal cells. Scale bars are $10 \mu \mathrm{m}$, valid for all panels

For statistical comparison of groups, one-way or twoway ANOVA followed by Tukey's post hoc test, or Kruskal-Wallis test followed by Dunn's multiple comparison test was used as applicable. For correlations, Spearman's correlation was used.

\section{Results}

\section{Validation of isoform-specific CaMKII antibodies}

Although the CaMKII antibodies used have been well characterized and shown to be specific for the respective isoform in the brain (e.g., Bachstetter et al. 2014; Ding et al. 2013; van Woerden et al. 2009), antibody specificity tests should preferentially be performed on the tissue of interest, as antigen cross-reactivity may be observed in only certain types or regions of tissue (Larsson et al. 2011). Therefore, spinal cord tissue from mice in which each isoform had been genetically ablated was used to validate the specificity and selectivity of the antibodies also in the spinal cord. Whereas wild-type mice showed strong CaMKII $\alpha$-like immunoreactivity (CaMKII $\alpha$-LI) in the superficial dorsal horn (as well as somewhat weaker and more scattered labeling of cell bodies and processes in deeper laminae), spinal cord sections from Camk $2 a^{-1-}$ mice were devoid of immunolabeling (Fig. 1a). CaMKII $\beta$ like immunoreactivity (CaMKII $\beta$-LI) was weak in wildtype mouse spinal cord sections, possibly because the tissue was too strongly fixed, and heat-mediated antigen retrieval was, therefore, used. This yielded a pattern of CaMKII $\beta$-LI in wild-type mouse spinal cord similar to that in rat spinal cord not subjected to antigen retrieval (Fig. 1b; see below); however, an additional weak immunolabeling over myelin was observed (not shown). No CaMKII $\beta$-LI was evident in cell bodies or neuropil in spinal cord from Camk $2 b^{-1-}$ mice, although some myelin-associated immunolabeling was observed also in this tissue. In rat spinal cord, neither CaMKII $\alpha$-LI nor CaMKII $\beta$-LI were observed in $\mathrm{Iba1}^{+}$microglial cell bodies (Fig. 1c), further confirming the specificity of both CaMKII antibodies in the rodent spinal cord.

\section{General distribution of CaMKII $\alpha$ and $\beta$ in the dorsal horn}

As described previously (Benson et al. 1992; Brüggemann et al. 2000; Terashima et al. 1994), CaMKII $\alpha$-LI was highly enriched in the neuropil of laminae I-II of the rat lumbar dorsal horn (Fig. 2b, e), although in the medial spinal cord, lamina IIo was somewhat less strongly labeled than the inner part of this lamina. Lamina III showed lower levels of immunoreactivity, whereas even weaker immunoreactivity was found in deeper laminae. The ventral limit of the neuropil enrichment of CaMKII $\alpha$-LI coincided with the border between laminae II and III, as assessed using dark field microscopy (Fig. 2a, b) and isolectin B4 binding (Fig. 2c, d). Nevertheless, despite weaker overall immunolabeling, cell bodies showing substantial immunoreactivity for CaMKII $\alpha$ were abundant also in lamina III and in deeper laminae of the dorsal horn (cf. Terashima et al. 1994). In some cell bodies, the nucleus (except the nucleolus) was prominently immunolabeled, whereas other cells had only very weakly immunolabeled nuclei. However, in a given cell, the nucleus was nearly always less strongly immunolabeled for CaMKII $\alpha$ than the cytoplasm. In the neuropil, some thick processes were outlined by immunoreactivity for CaMKII $\alpha$; some of these were strongly labeled, whereas others were more weakly labeled than the surrounding tissue.

In contrast to $\mathrm{CaMKII} \alpha$, CaMKII $\beta$-like immunoreactivity (CaMKII $\beta$-LI) in the dorsal horn was relatively evenly distributed throughout the dorsal horn (Fig. 2c, f). Apart from a slightly weaker labeling in medial lamina IIo, there was no visually discernible difference in either neuropil or somatic staining between different laminae. Although the strength of cytoplasmic CaMKII $\beta$-LI varied substantially between neuronal cell bodies, most nuclei showed very weak or undetectable staining. CaMKII $\beta$-LI had a fine granular appearance both in neuropil and somata, whereas CaMKII $\alpha$-LI was more diffuse and concentrated in larger puncta or processes (Fig. 3). Furthermore, considering the supposed co-assembly of CaMKII $\alpha$ and CaMKII $\beta$ into heterooligomers, the overlap in the neuropil between CaMKII $\alpha$-LI and CaMKII $\beta$-LI was relatively incomplete. For instance, whereas some elongated processes co-localized substantial CaMKII $\alpha$-LI and CaMKII $\beta$ - 
LI, other such processes with strong CaMKII $\beta$-LI showed poor labeling for CaMKII $\alpha$ (Fig. 3) and vice versa (not shown).

\section{CaMKII isoforms in excitatory and inhibitory neurons}

An immunofluorescence protocol was established to coimmunolabel for CaMKII $\alpha$ and CaMKII $\beta$ together with $\mathrm{NeuN}$ as a pan-neuronal marker and Pax2 as a marker for inhibitory neurons in the same spinal cord sections (Fig. 4). In an initial selection of $\mathrm{NeuN}^{+}$cells, Pax2 immunolabeling was detected in $26,29,33$, and $18 \%$ of cells in laminae I, IIo, IIi, and III, respectively. Additional cells were then analyzed to yield 100 each of $\mathrm{Pax}^{+}$and Pax2 ${ }^{-}$ cells in each lamina. In laminae I-III, somatic labeling for CaMKII $\alpha$ varied widely between neurons; some showed strong immunolabeling, whereas in others, the immunolabeling was barely detectable. Similarly, somatic CaMKII $\beta$ LI varied between neurons from very weak to very strong. Notably, ependymal cells lining the central canal showed essentially no immunolabeling for CaMKII $\alpha$ or CaMKII $\beta$, suggesting that even the very weak immunolabeling of some neurons reflected the presence of the respective isoform rather than constituting unspecific labeling of cellular elements. Indeed, quantitative analysis showed that the most weakly immunolabeled neurons were more than threefold more strongly labeled for either isoform than were ependymal cells, whose normalized CaMKII $\alpha$-LI and CaMKII $\beta$-LI were $0.07 \pm 0.009$ (mean $\pm \mathrm{SD} ; n=60$ cells) and $0.11 \pm 0.03$ times tissue average, respectively (Fig. 5a).

Further quantitative analysis showed that Pax2- (presumed excitatory) neurons in lamina I, dorsal lamina II (IIo) and ventral lamina II (IIi) had similar levels of CaMKII $\alpha$-LI, whereas lamina III Pax2 $2^{-}$neurons were on average considerably less immunolabeled (Fig. 5a). Similarly, among $\mathrm{Pax}^{+}$(presumed inhibitory) neurons, those in laminae I-II were on average more strongly immunolabeled for CaMKII $\alpha$ than were those in lamina III. Notably, $\mathrm{Pax}^{+}$neurons showed similar or only slightly weaker CaMKIII $\alpha$-LI than Pax $2^{-}$neurons in the same lamina. For CaMKII $\beta$-LI, among Pax $2^{-}$neurons, those in lamina IIi showed weaker average immunolabeling than those in a

CaMKII $\alpha$

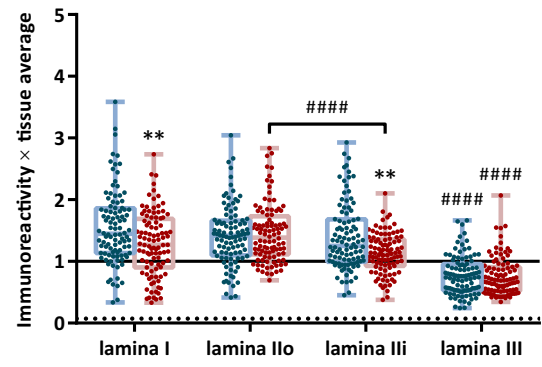

C

lamina I

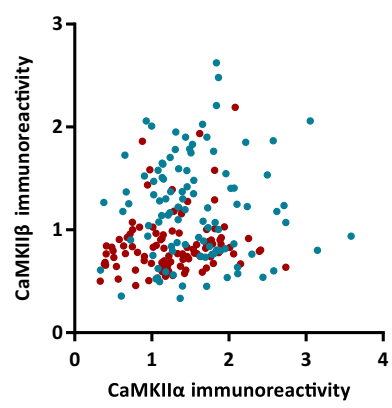

Fig. 5 Quantitative analysis of CaMKII $\alpha$-LI and CaMKII $\beta$-LI in excitatory and inhibitory dorsal horn neurons. a CaMKII $\alpha$-LI and CaMKII $\beta$-LI normalized against the average intensity over laminae IIII in $\mathrm{Pax}^{-}$and $\mathrm{Pax}^{+}$neurons in laminae I-III. Solid horizontal lines indicate average tissue labeling over laminae I-III. Dashed lines indicate average immunolabeling over ependymal cells lining the central canal. b Ratio of normalized CaMKII $\alpha$-LI over normalized CaMKII $\beta$-LI in $\mathrm{Pax}^{-}$and $\mathrm{Pax}^{+}$neurons in laminae I-III. Asterisks lamina Ilo

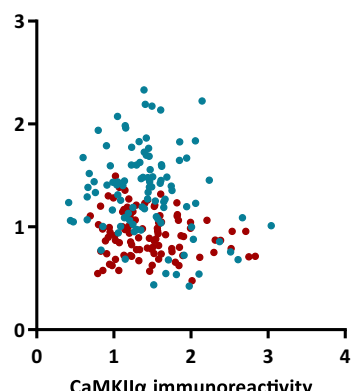

b
CaMKII $\beta$

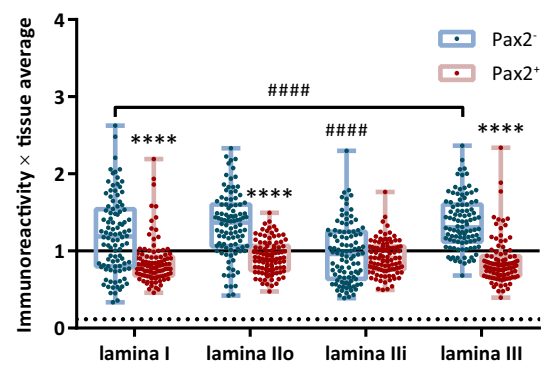

CaMKII $\alpha$ / CaMKII

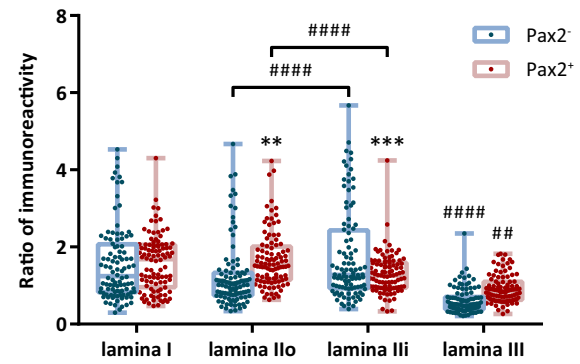

lamina Ili

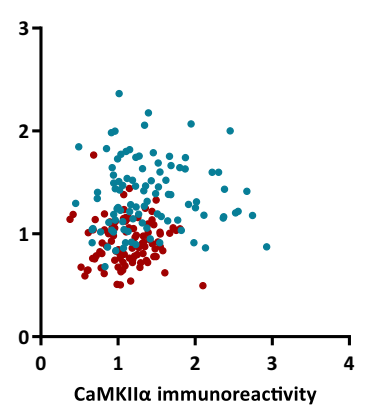

lamina III

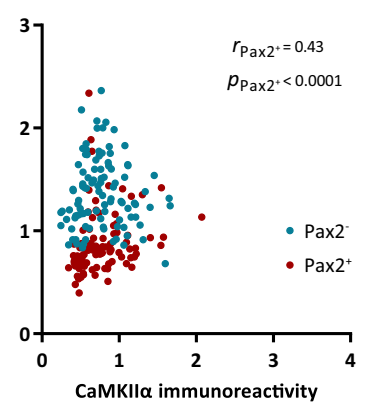

in $\mathbf{a}$ and $\mathbf{b}$ indicate statistical comparison between $\mathrm{Pax} 2^{-}$and $\mathrm{Pax} 2^{+}$ cells within the same lamina, whereas hashes indicate statistical comparisons between laminae within either the $\mathrm{Pax} 2^{-}$or the $\mathrm{Pax} 2^{+}$ group. $* * / \# \# p<0.01$; $* * * p<0.001$; $* * * * \# \# \#+0.0001$; two-way ANOVA followed by Tukey's post hoc test. c scatterplots of normalized CaMKII $\beta$-LI versus normalized CaMKII $\alpha$-LI in each lamina. Correlations were assessed using Spearman's correlation. Only $\mathrm{Pax} 2^{+}$neurons in lamina III were weak correlation detected 
other laminae. However, $\operatorname{Pax}^{+}$neurons generally exhibited considerably weaker CaMKII $\beta$-LI than Pax $2^{-}$neurons in all laminae except for lamina IIi, where the lack of difference could be attributed to the weak labeling also in Pax $2^{-}$neurons. Notably, a similar pattern of CaMKII $\alpha$-LI and CaMKII $\beta$-LI between Pax $2^{-}$and $\mathrm{Pax} 2^{+}$neurons in different laminae was found in an additional experiment analyzed using manual scoring (Tables 2,3 ).

As the subunit composition of CaMKII heteromers is stochastically determined on the basis of the relative expression of the different isoforms (Shen et al. 1998), it is of interest to assess the ratio of CaMKII $\alpha$-LI to CaMKII $\beta$ LI. Although the absolute ratio of expression could not be determined (as the immunolabeling efficiency for each isoform was unknown), it was possible to semi-quantitatively compare the ratio of immunolabeling between different profiles. Surprisingly, in both lamina IIo and lamina III, Pax $2^{+}$neurons had a higher CaMKII $\alpha$-LI-to-CaMKII $\beta$ -
LI ratio than $\mathrm{Pax}^{-}$neurons (Fig. 5b). In lamina IIi, the mean ratio was similar between $\mathrm{Pax} 2^{+}$and $\mathrm{Pax} 2^{-}$neurons, but among the latter, a subpopulation showed a high ratio of CaMKII $\alpha$-LI to CaMKII $\beta$-LI. Scatter plots revealed no or only weak correlation between CaMKII $\alpha$-LI and CaMKII $\beta$-LI within different neuronal populations (Fig. 5c).

Whereas the proportion of $\mathrm{Pax}^{+}$neurons in laminae III were in accordance with the frequency of inhibitory neurons in these laminae, the proportion of $\mathrm{Pax}^{+}$cells in lamina III was lower than expected (Polgár et al. 2003; Todd and Sullivan 1990). However, for detection of Pax2 immunolabeling, a secondary antibody conjugated to Alexa Fluor 405 was used, which resulted in relatively weak immunofluorescence. In a separate NeuN/Pax2 double labeling experiment where Pax 2 immunofluorescence was detected using Alexa Fluor 568, many $\mathrm{NeuN}^{+}$cells, in particular in lamina III, were only weakly labeled for Pax2; such cells may have been undetected when using the Alexa

Table 2 CaMKII $\alpha-\mathrm{LI}$ in Pax $2^{-}$and $\mathrm{Pax} 2^{+}$neurons analyzed by manual scoring

\begin{tabular}{|c|c|c|c|c|c|c|c|c|}
\hline \multirow[t]{3}{*}{ Score } & \multicolumn{8}{|l|}{ Lamina } \\
\hline & \multicolumn{2}{|l|}{ I } & \multicolumn{2}{|l|}{ IIo } & \multicolumn{2}{|l|}{ III } & \multicolumn{2}{|l|}{ III } \\
\hline & $\begin{array}{l}\operatorname{Pax}^{-}(136) \\
(\%)\end{array}$ & $\begin{array}{l}\operatorname{Pax} 2^{+}(32) \\
(\%)\end{array}$ & $\begin{array}{l}\mathrm{Pax}^{-}(188) \\
(\%)\end{array}$ & $\begin{array}{l}\operatorname{Pax}^{+}(72) \\
(\%)\end{array}$ & $\begin{array}{l}\operatorname{Pax}^{-}(104) \\
(\%)\end{array}$ & $\begin{array}{l}\operatorname{Pax}^{+}(82) \\
(\%)\end{array}$ & $\begin{array}{l}\operatorname{Pax}^{-}(75) \\
(\%)\end{array}$ & $\begin{array}{l}\operatorname{Pax}^{+}(59) \\
(\%)\end{array}$ \\
\hline 0 & 0 & 1.7 & 0 & 0 & 0 & 0 & 1.3 & 8.5 \\
\hline 1 & 11.0 & 24.6 & 12.8 & 15.3 & 14.4 & 31.7 & 66.7 & 54.2 \\
\hline 2 & 53.5 & 45.6 & 52.7 & 70.8 & 65.4 & 64.6 & 30.7 & 35.6 \\
\hline 3 & 27.5 & 28.0 & 29.8 & 13.9 & 18.3 & 3.7 & 1.3 & 1.7 \\
\hline 4 & 8.0 & 0 & 4.8 & 0 & 1.9 & 0 & 0 & 0 \\
\hline $\begin{array}{l}\text { Statistical } \\
\text { significance }\end{array}$ & & & & & $*$ & & & \\
\hline
\end{tabular}

Number of neurons analyzed in each group is indicated in parentheses. ${ }^{*} p<0.05$; Kruskal-Wallis test followed by Dunn's post hoc test (withinlamina comparisons)

Table 3 CaMKII $\beta$-LI in Pax $2^{-}$and $\mathrm{Pax} 2^{+}$neurons analyzed by manual scoring

\begin{tabular}{|c|c|c|c|c|c|c|c|c|}
\hline \multirow[t]{3}{*}{ Score } & \multicolumn{8}{|l|}{ Lamina } \\
\hline & \multicolumn{2}{|l|}{ I } & \multicolumn{2}{|l|}{ IIo } & \multicolumn{2}{|l|}{ IIi } & \multicolumn{2}{|l|}{ III } \\
\hline & $\begin{array}{l}\operatorname{Pax}^{-}(168) \\
(\%)\end{array}$ & $\begin{array}{l}\operatorname{Pax}^{+}(47) \\
(\%)\end{array}$ & $\begin{array}{l}\operatorname{Pax}^{-}(188) \\
(\%)\end{array}$ & $\begin{array}{l}\operatorname{Pax}^{+}(72) \\
(\%)\end{array}$ & $\begin{array}{l}\operatorname{Pax}^{-}(104) \\
(\%)\end{array}$ & $\begin{array}{l}\operatorname{Pax}^{+}(82) \\
(\%)\end{array}$ & $\begin{array}{l}\operatorname{Pax}^{-}(75) \\
(\%)\end{array}$ & $\begin{array}{l}\mathrm{Pax}^{+}(59) \\
(\%)\end{array}$ \\
\hline 0 & 0 & 0 & 0 & 0 & 0 & 0 & 0 & 0 \\
\hline 1 & 8.0 & 17.5 & 16.5 & 20.8 & 25.0 & 28.0 & 9.3 & 37.3 \\
\hline 2 & 48.5 & 68.4 & 23.9 & 58.3 & 47.1 & 68.3 & 40.0 & 45.8 \\
\hline 3 & 29.5 & 14.0 & 46.8 & 20.8 & 27.9 & 3.7 & 49.3 & 16.9 \\
\hline 4 & 14.0 & 0 & 12.8 & 0 & 0 & 0 & 1.3 & 0 \\
\hline $\begin{array}{l}\text { Statistical } \\
\text { significance }\end{array}$ & $*$ & & $* * * *$ & & & & $* * * *$ & \\
\hline
\end{tabular}

Number of neurons analyzed in each group is indicated in parentheses. $* p<0.05$; $* * p<0.01 ; * * * p<0.0001$; Kruskal-Wallis test followed by Dunn's post hoc test (within-lamina comparisons) 

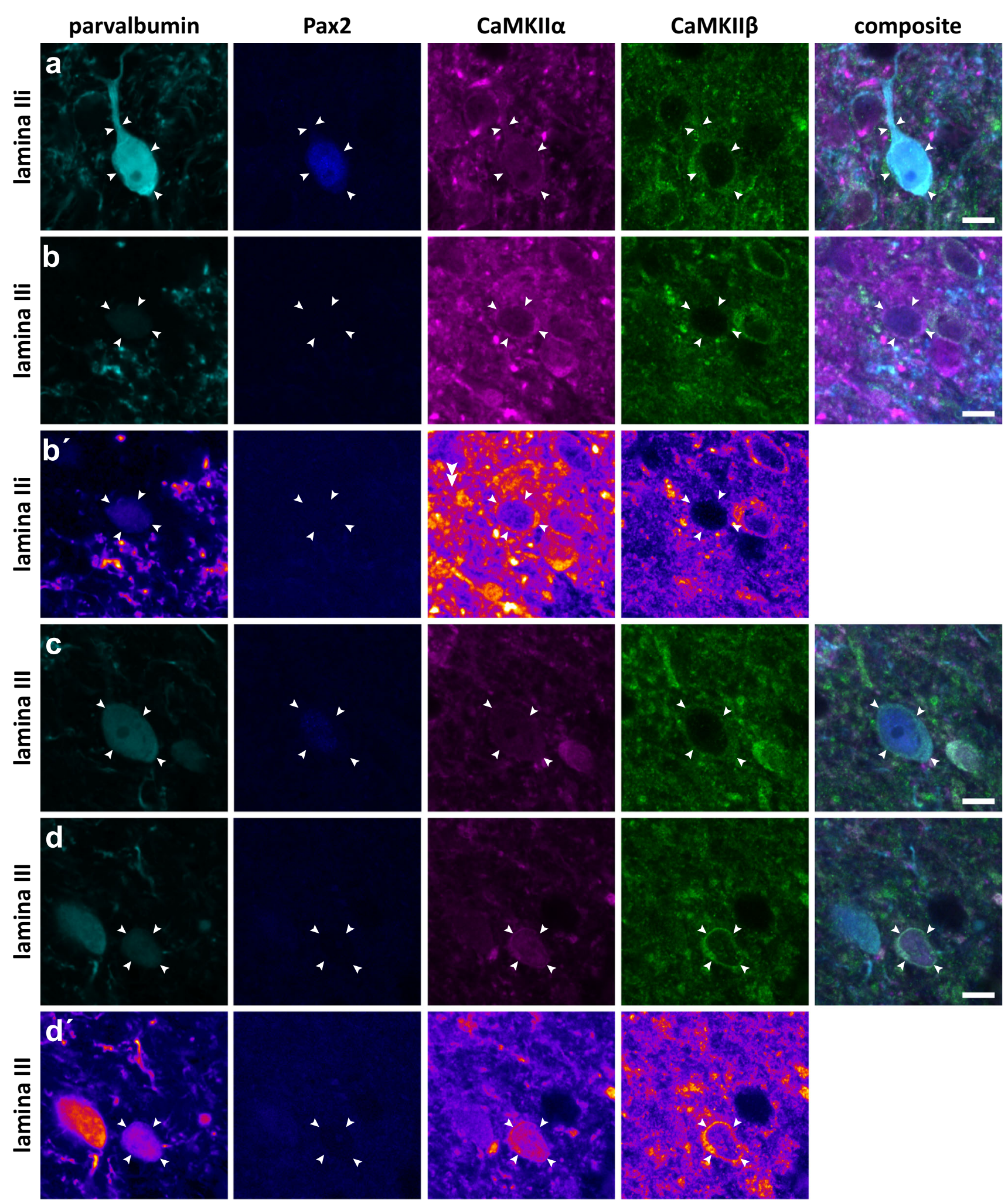
4Fig. 6 CaMKII $\alpha$-LI and CaMKII $\beta$-LI in parvalbumin neurons. Indicated by arrowheads are examples of parvalbumin immunolabeled cells in laminae IIi and III that differentially label for Pax2, CaMKII $\alpha$, and CaMKII $\beta$. a Pax $2^{+}$, presumed inhibitory parvalbumin cell in lamina IIi with considerable CaMKII $\alpha$-LI and CaMKII $\beta$-LI. b, $\mathbf{b}^{\prime} \mathrm{Pax}^{-}$, presumed excitatory, weakly parvalbumin immunopositive cell in lamina IIi exhibiting strong CaMKII $\alpha$-LI and weak CaMKII $\beta$ LI. In $\mathbf{b}^{\prime}$, a false-color look-up table was applied to better visualize the weak parvalbumin and cytoplasmic CaMKII $\beta$ immunolabeling. Note the apparent lack of nuclear CaMKII $\beta$-LI. c Pax2 $2^{+}$parvalbumin neuron in lamina III showing weak CaMKII $\alpha$-LI and CaMKII $\beta$-LI. d, $\mathbf{d}^{\prime} \mathrm{Pax}^{-}$parvalbumin neuron in lamina III showing moderate CaMKII $\alpha$-LI and CaMKII $\beta$-LI. $\mathbf{d}^{\prime}$ Same neuron as in d using a falsecolor look-up table to enhance the visibility of the parvalbumin labeling. Scale bars, $5 \mu \mathrm{m}$, valid for all panels

Fluor 405 fluorophore. Indeed, 23 of $50 \mathrm{NeuN}^{+}$cells (46\%) in lamina III were strongly or weakly Pax2 immunopositive in NeuN/Pax2 double immunolabeled tissue, in line with the previous estimates of the proportion of GABAergic cells in lamina III (Polgár et al. 2003; Todd and Sullivan 1990).

\section{CaMKII isoforms in parvalbumin neurons}

Parvalbumin neurons are considered to constitute a relatively homogeneous population of inhibitory neurons in the superficial dorsal horn, although a subset of parvalbumin neurons has been reported to be non-GABAergic and thus presumably glutamatergic, at least in the rat (Antal et al. 1991; Laing et al. 1994). To determine the expression of CaMKII $\alpha$ and CaMKII $\beta$ in parvalbumin neurons of inhibitory and excitatory phenotypes, spinal cord sections were immunolabeled for the CaMKII isoforms, parvalbumin, and Pax2. Parvalbumin neurons were found both in lamina IIi, embedded in the plexus of parvalbumin processes residing in this part of the dorsal horn, and in lamina III ventral to the parvalbumin plexus. In keeping with the previous observations (Antal et al. 1991; Laing et al. 1994), a proportion of parvalbumin neurons in lamina IIi (26\%; $27 / 102$ cells) and in lamina III (42\%; 53/126 cells) were found to lack Pax 2 and were, therefore, assumed to be excitatory. Thus, for the purpose of this analysis, parvalbumin neurons were divided into four subpopulations, based on Pax 2 expression and location in either lamina IIi or lamina III.

As was the case for $\mathrm{NeuN}^{+}$neurons, parvalbumin neurons exhibited highly variable levels of CaMKII $\alpha$-LI and CaMKII $\beta$-LI (Fig. 6). Pax $2^{+}$neurons in either lamina IIi or III exhibited, on average, lower levels of CaMKII $\alpha$-LI than Pax $2^{-}$neurons in the same lamina, although neurons in lamina III had weak staining compared to those with the same Pax2 phenotype in lamina IIi (Fig. 7a). By contrast, the pattern of immunolabeling of neurons in lamina IIi and
III diverged with respect to CaMKII $\beta$. All subpopulations showed weak immunoreactivity for this subunit, except Pax $2^{-}$neurons in lamina III, which exhibited comparatively strong CaMKII $\beta$-LI (cf. Fig. 5). Pax $2^{-}$neurons in lamina IIi showed a conspicuously high CaMKII $\alpha$-toCaMKII $\beta$ ratio as compared to the other populations (Fig. 7b).

Given that somatic CaMKII $\alpha$-LI and CaMKII $\beta$-LI was weaker in the nucleus as compared to the cytoplasm, it is possible that some of the measured differences in somatic immunolabeling between populations could be attributed to differences in the ratio of cytoplasm area to nucleus area between neurons. To test this for parvalbumin neurons, cytoplasmic labeling was obtained for each neuron. The patterns of cytoplasmic immunolabeling for both CaMKII $\alpha$-LI and CaMKII $\beta$-LI were very similar to those of total somatic labeling (Fig. 7a-d), indicating that the observed differences in immunolabeling between neuronal populations were not to a large extent attributed to differences in cytoplasm-to-nucleus ratio, at least in the case of parvalbumin neurons.

In lamina III, a strong correlation between CaMKII $\beta$-LI and CaMKII $\alpha$-LI was found in $\mathrm{Pax}^{+}$parvalbumin neurons; a weaker correlation was also found in $\mathrm{Pax} 2^{+}$neurons in lamina IIi, whereas no correlations were observed for Pax2 $2^{-}$neurons (Fig. 7e).

During the analysis of CaMKII labeling in parvalbumin neurons, it was noted that parvalbumin expression appeared related to the expression of Pax2, in that all Pax $2^{-}$neurons showed weak parvalbumin immunolabeling, whereas neurons with strong parvalbumin expression always were $\mathrm{Pax}^{+}$. Indeed, quantitative analysis showed that Pax $2^{-}$neurons in both laminae IIi and III invariably had weak parvalbumin expression, whereas parvalbumin expression in $\mathrm{Pax}^{+}$neurons was highly variable (Fig. 7f).

\section{CaMKII isoforms in calretinin neurons}

Calretinin immunolabeling in the spinal cord was as previously described (Ren and Ruda 1994). Few calretinin immunolabeled neurons were found in lamina III, and analysis was, therefore, constrained to laminae I-II. Some reports have suggested that a small population of calretinin neurons are GABAergic in the mouse dorsal horn (Huang et al. 2010; Smith et al. 2015) and in isolated embryonic rat dorsal horn neurons (Albuquerque et al. 1999). However, to my knowledge, this issue has not been investigated in the intact rat spinal cord. Thus, spinal cord sections immunolabeled for calretinin, Pax2, CaMKII $\alpha$, and CaMKII $\beta$ were specifically examined with respect to calretinin/ Pax2 co-localization. Eight percent (7/86), 12\% (28/235), and 5\% (11/226) of calretinin neurons were immunopositive for Pax2 in lamina I, lamina IIo, and lamina IIi, 
a

\section{CaMKII $\alpha$}

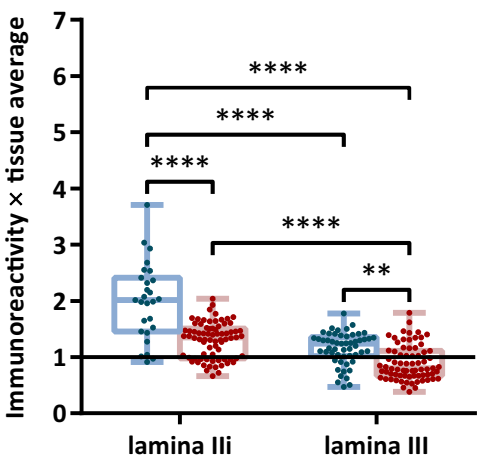

C

cytosolic CaMKII $\alpha$

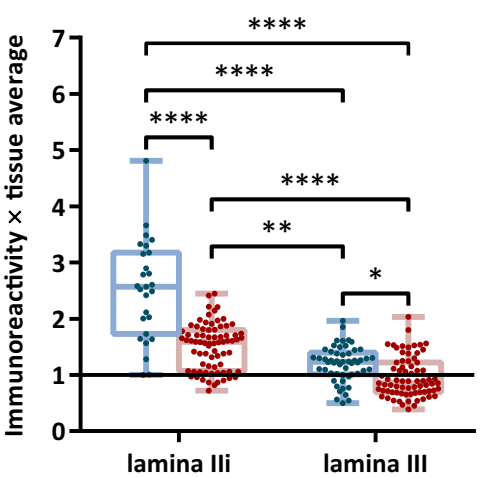

e

lamina Ili

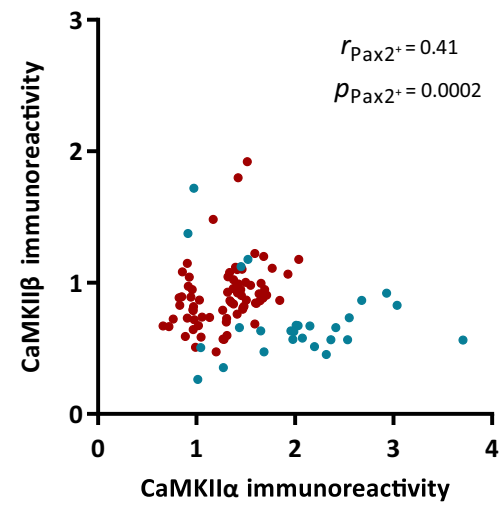

CaMKIIß

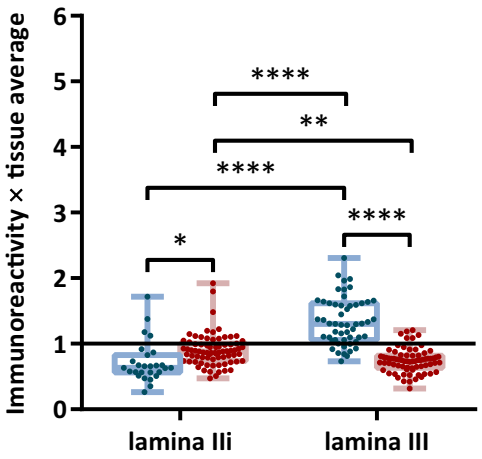

cytosolic CaMKII $\beta$

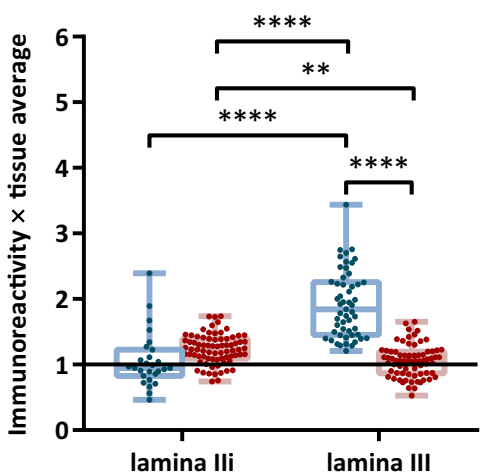

lamina III

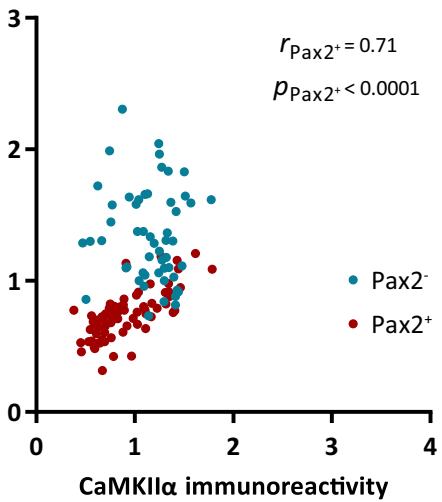

b

CaMKII $\alpha$ / CaMKII $\beta$

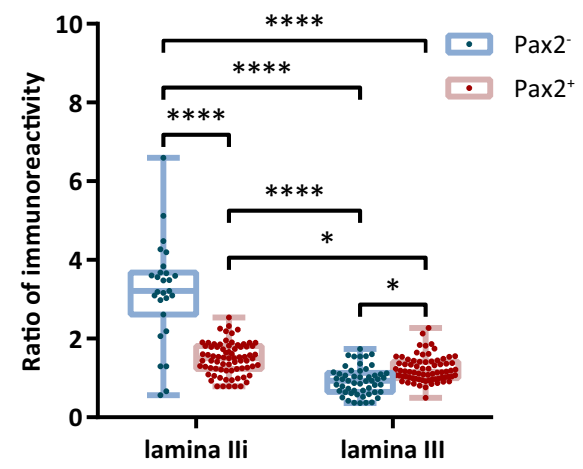

d cytosolic CaMKII $\alpha$ / CaMKII $\beta$

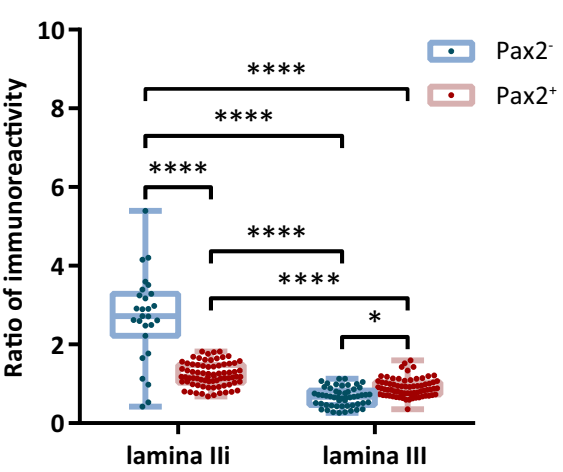

f

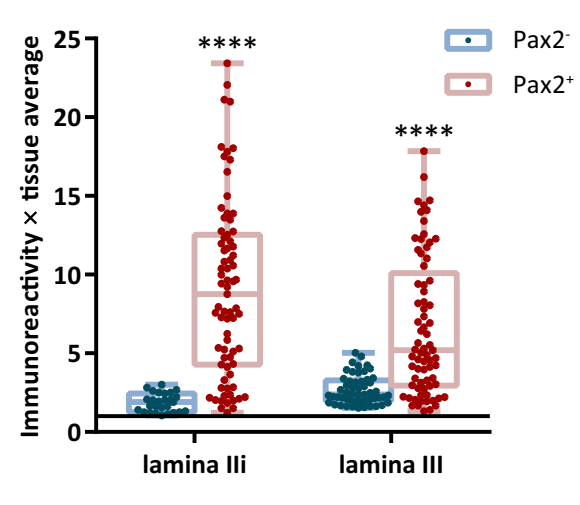


4Fig. 7 Quantitative analysis of CaMKII $\alpha$-LI and CaMKII $\beta$-LI in parvalbumin neurons. a Total somatic CaMKII $\alpha$-LI and CaMKII $\beta$-LI normalized against the average intensity over laminae I-III in Pax2 ${ }^{-}$ and $\mathrm{Pax}^{+}$parvalbumin neurons in laminae IIi and III. Solid horizontal lines indicate average tissue labeling over laminae I-III. b Ratio of normalized CaMKII $\alpha$-LI over normalized CaMKII $\beta$-LI in $\mathrm{Pax}^{-}$and $\mathrm{Pax}^{+}$neurons in laminae IIi and III. c Cytosolic CaMKII $\alpha$-LI and CaMKII $\beta$-LI normalized against the average intensity over laminae I-III in $\mathrm{Pax} 2^{-}$and $\mathrm{Pax} 2^{+}$parvalbumin neurons in laminae IIi and III. Solid horizontal lines indicate average tissue labeling over laminae I-III. d Ratio of normalized CaMKII $\alpha$-LI over normalized CaMKII $\beta$-LI in the cytosol of Pax2 $2^{-}$and Pax $2^{+}$ neurons in laminae III and III. * $p<0.05$; ** $p<0.01$; *** $p<0.001$; $* * * * p<0.0001$; two-way ANOVA followed by Tukey's post hoc test. e Scatterplots of normalized CaMKII $\beta$-LI versus normalized CaMKII $\alpha$-LI in $\mathrm{Pax}^{+}$and $\mathrm{Pax}^{-}$parvalbumin neurons in each lamina. Correlations were statistically evaluated using Spearman's correlation. Note the strong positive correlation in Pax $2^{+}$neurons in lamina III, and the moderate correlation in such neurons in lamina IIi. f Parvalbumin immunoreactivity in $\mathrm{Pax}^{-}$and $\mathrm{Pax} 2^{+}$parvalbumin neurons, normalized against laminae I-III tissue average (indicated by solid line). $* * * * p<0.0001$; two-way ANOVA followed by Sidak's post hoc test of selected groups (Pax2 $2^{-}$versus $\mathrm{Pax} 2^{+}$in each lamina) respectively. Thus, a minor fraction of calretinin neurons are presumably GABAergic also in the rat dorsal horn.

As the number of sampled Pax $2^{+}$calretinin neurons was very low in lamina I and lamina IIi, in the following, only $\mathrm{Pax} 2^{+}$neurons in lamina IIo will be considered. In Pax $2^{-}$ neurons, CaMKII $\alpha$-LI was generally moderate-to-strong (Figs. 8, 9a), similar to the levels found in NeuN/Pax2 $2^{-}$ neurons in the same lamina (cf Fig. 5a). However, Pax $2^{+}$ calretinin neurons were, on average, more strongly immunolabeled for CaMKII $\alpha$ than were $\mathrm{Pax} 2^{-}$calretinin neurons.

Among Pax $2^{-}$calretinin neurons, CaMKII $\beta$-LI was, on average, strongest in lamina IIo. However, $\mathrm{Pax}^{+}$calretinin neurons exhibited substantially lower levels of CaMKII $\beta$-LI than did $\mathrm{Pax}^{-}$calretinin neurons. As expected given the high levels of CaMKII $\alpha$-LI and low levels of CaMKII $\beta$-LI in $\mathrm{Pax}^{+}$calretinin neurons in lamina IIo, the ratio of CaMKII $\alpha$-LI to CaMKII $\beta$-LI was considerably higher in this population compared to Pax2 $2^{-}$ calretinin neurons (Fig. 9b). Nevertheless, especially in lamina II, a subpopulation of $\mathrm{Pax} 2^{-} /$calretinin neurons with high CaMKII $\alpha$-LI-to-CaMKII $\beta$-LI ratio was also
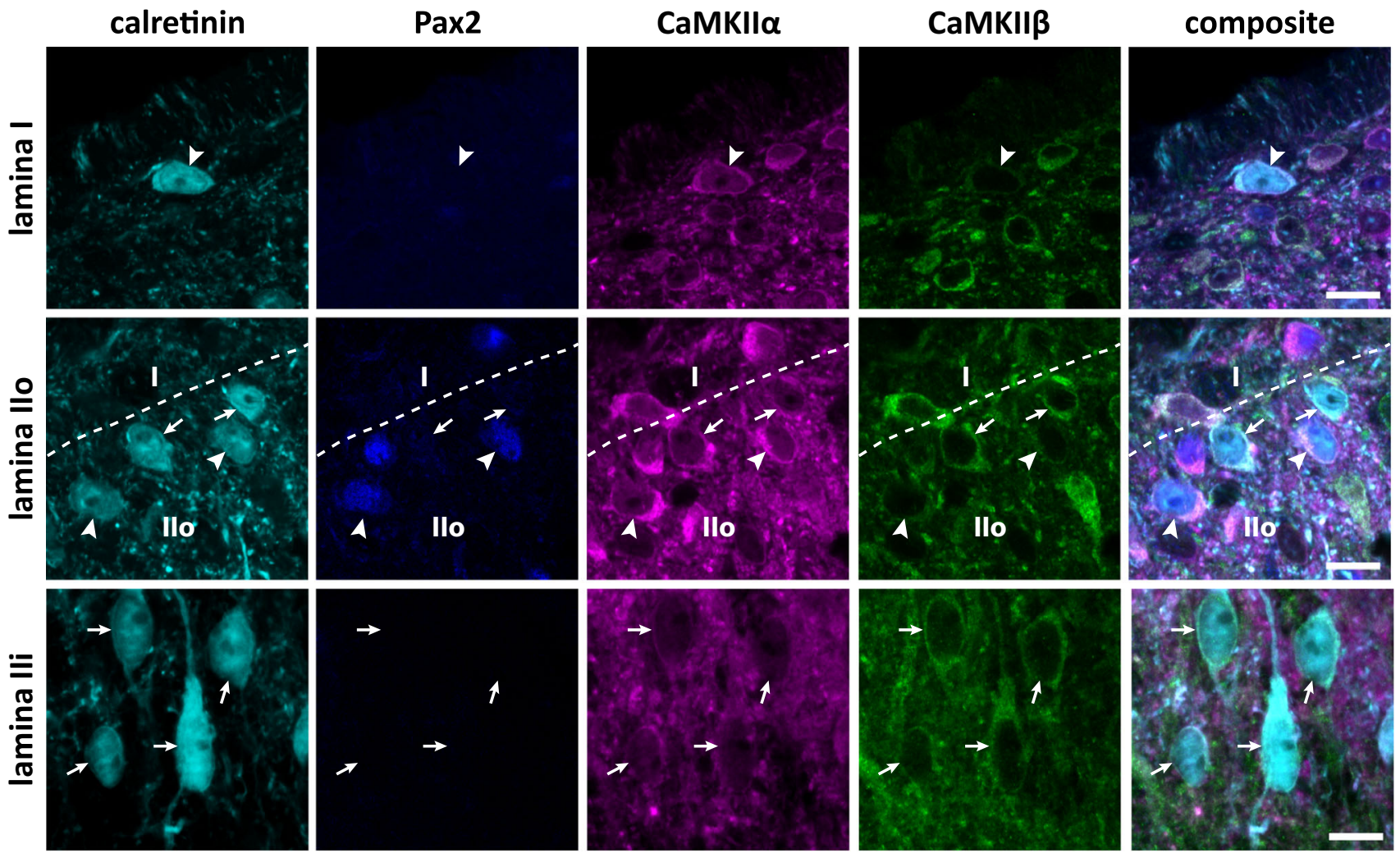

Fig. $8 \mathrm{CaMKII} \alpha-\mathrm{LI}$ and CaMKII $\beta$-LI in calretinin neurons. Indicated are examples of calretinin immunolabeled cells in laminae I-IIi that differentially label for Pax2, CaMKII $\alpha$, and CaMKII $\beta$. In lamina I, arrowhead indicates a Pax $2^{-}$calretinin neuron with strong CaMKII $\alpha$ LI and weak CaMKII $\beta$-LI. In lamina IIo, arrowheads indicate two $\mathrm{Pax}^{+}$calretinin neurons with strong CaMKII $\alpha$-LI and weak
CaMKII $\beta$-LI, whereas arrows indicate $\mathrm{Pax} 2^{-}$neurons that exhibit considerable CaMKII $\alpha$-LI and CaMKII $\beta$-LI. Dashed line indicates border between laminae I and IIo. In lamina IIi, arrows indicate several neurons with moderate CaMKII $\alpha$-LI and CaMKII $\beta$-LI. Scale bars are $5 \mu \mathrm{m}$, valid for all panels 
a

\section{CaMKII $\alpha$}

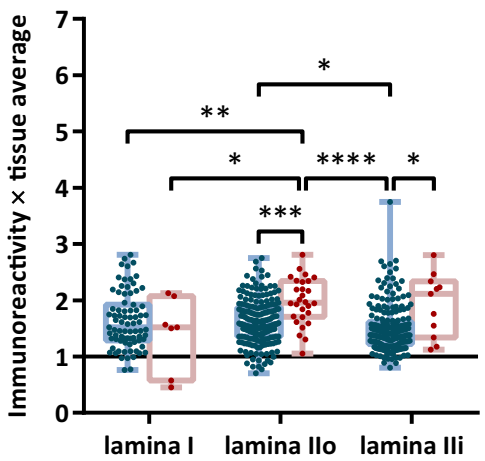

C

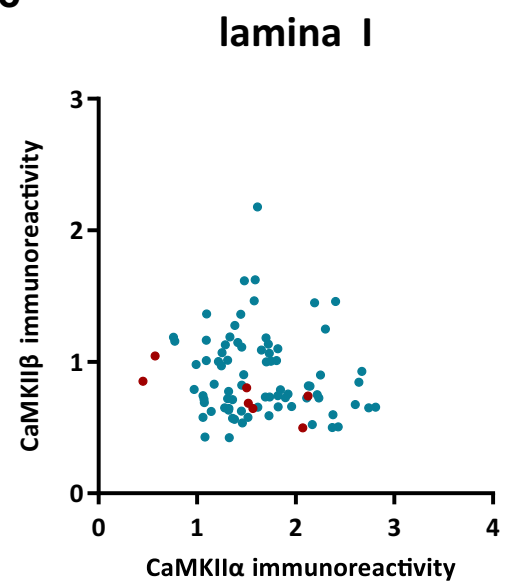

CaMKIIß

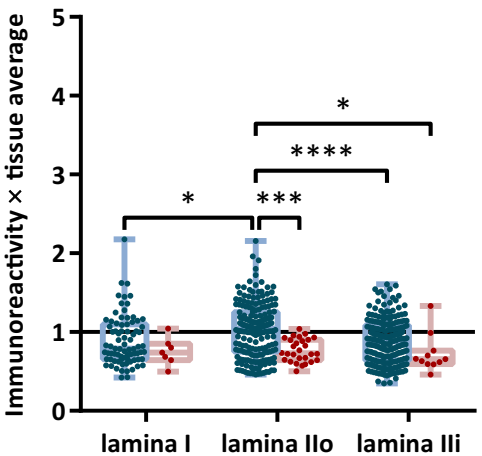

lamina Ilo

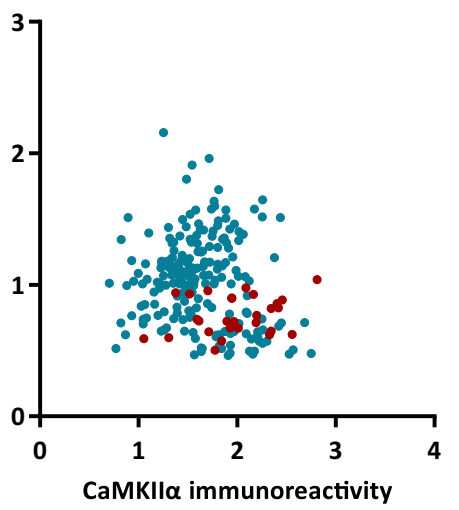

b

\section{CaMKII $\alpha$ / CaMKII $\beta$}

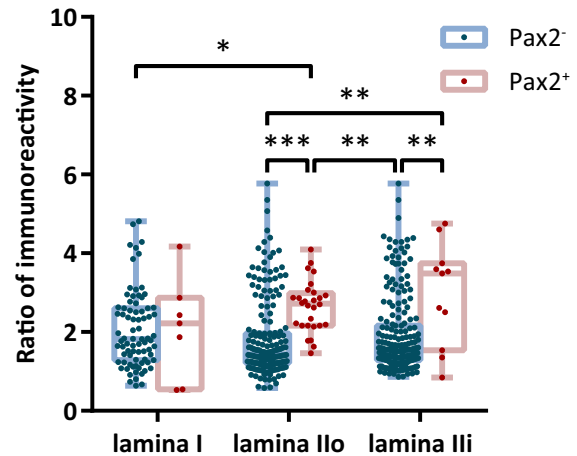

lamina Ili

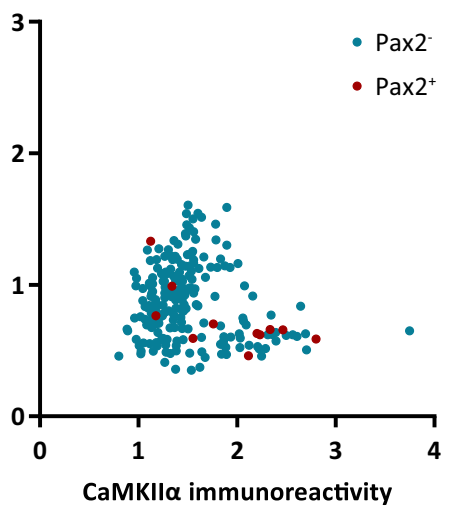

Fig. 9 Quantitative analysis of CaMKII $\alpha$-LI and CaMKII $\beta$-LI in calretinin neurons. a CaMKII $\alpha$-LI and CaMKII $\beta$-LI normalized against the average intensity over laminae I-III in Pax2 $2^{-}$and $\mathrm{Pax}^{+}$ calretinin neurons in laminae I-IIi. Solid horizontal lines indicate average tissue labeling over laminae I-III. b Ratio of normalized CaMKII $\alpha$-LI over normalized CaMKII $\beta$-LI in $\mathrm{Pax}^{-}$and $\mathrm{Pax}^{+}$

evident. No correlation between CaMKII $\beta$-LI and CaMKII $\alpha$-LI was found in any population (Fig. 9c).

\section{CaMKII isoforms in calbindin D28k neurons}

In an initial survey, 7.5\% (29/382) of calbindin D28k neurons in laminae I-III was found to co-express Pax2, a fraction which was somewhat higher than the reported proportion of calbindin D28k neurons in the rat dorsal horn that contain GABA (Antal et al. 1991). Nevertheless, the number of $\mathrm{Pax}^{+}$calbindin D28k neurons in each lamina was low and further quantitative analysis was, therefore, restricted to calbindin D28k neurons that did not express Pax2.

Calbindin D28k neurons in lamina IIo showed on average higher CaMKII $\alpha$-LI than did such neurons in other laminae (Figs. 10, 11). However, although calbindin D28k calretinin neurons in laminae I-IIi. * $p<0.05 ; * * p<0.01$; $* * * p<0.001 ; * * * * p<0.0001$; two-way ANOVA followed by Tukey's post hoc test. c Scatterplots of normalized CaMKII $\beta$-LI versus normalized CaMKII $\alpha$-LI in each lamina. Correlations were assessed using Spearman's correlation. No statistically significant correlations were detected

neurons in lamina III showed the weakest CaMKII $\alpha$-LI, the immunolabeling in these neurons relative to tissue average was considerably higher than in $\mathrm{NeuN}^{+} / \mathrm{Pax} 2^{-}$neurons in this lamina (cf Fig. 5). In the case of CaMKII $\beta$-LI, immunolabeling was stronger in both lamina I and III as compared to either dorsal or ventral lamina II. The levels of CaMKII $\beta$-LI relative to tissue average were, in all laminae, lower than $\mathrm{NeuN}^{+} / \mathrm{Pax}^{-}$neurons in the same laminae (cf. Fig. 5). Median CaMKII $\alpha$-LI-to-CaMKII $\beta$-LI ratio in calbindin D28k neurons in lamina IIo and III was 84 and $98 \%$ higher, respectively, than in $\mathrm{NeuN}^{+} / \mathrm{Pax}^{-}$neurons in the same laminae.

\section{CaMKII isoforms at postsynaptic sites}

The pool of CaMKII within the postsynaptic density is thought to be pivotal in synaptic plasticity mechanisms 
(Lisman et al. 2012; Coultrap and Bayer 2012), and it is, therefore, of interest to map this pool in the dorsal horn. However, proteins within the postsynaptic density at glutamatergic synapses are generally not accessible to antibodies with common immunofluorescence procedures. Nevertheless, pepsin-mediated antigen retrieval provides a means to reveal such postsynaptic proteins, generally at the expense of non-synaptic proteins, by degrading surrounding proteins (Larsson et al. 2013; Nagy et al. 2004; Polgár et al. 2008; Watanabe et al. 1998). Pepsin treatment was, therefore, used to investigate postsynaptic CaMKII isoforms at dorsal horn synapses. The AMPA receptor subunit GluA2 was used as a synaptic marker, as this subunit is present at all or essentially all glutamatergic synapses in the dorsal horn (Nagy et al. 2004; Polgár et al. 2008). GluA2 labeling at the surface of pepsin-treated sections through the dorsal horn was punctate and showed a distribution similar to what has been previously described (Larsson et al. 2013; Nagy et al. 2004; Polgár et al. 2008). CaMKII $\alpha$ and CaMKII $\beta$ immunoreactive puncta often colocalized with GluA2 ${ }^{+}$puncta (Fig. 12a). However, substantial CaMKII $\alpha$-LI and CaMKII $\beta$-LI not associated with GluA2 ${ }^{+}$puncta were also observed, indicating that some pools of non-synaptic CaMKII were resistant to pepsinmediated degradation under the conditions used here. Moreover, many GluA2 ${ }^{+}$puncta showed weak or undetectable labeling for CaMKII $\alpha$ and CaMKII $\beta$. In accordance with the low overall levels of CaMKII $\alpha$-LI in lamina III, many GluA2 ${ }^{+}$puncta showed very low or no labeling for CaMKII $\alpha$ in this lamina. Notably, the intensities of CaMKII $\alpha$-LI and CaMKII $\beta$-LI at GluA2 ${ }^{+}$puncta appeared to co-vary throughout the superficial dorsal horn. Indeed, quantitative analysis showed strong positive correlation between CaMKII $\alpha$-LI and CaMKII $\beta$-LI at GluA2 ${ }^{+}$puncta in all laminae (Fig. 12b).

\section{Discussion}

One of the most salient observations was that CaMKII $\alpha$ was expressed in all or nearly all neurons in laminae I-III, and at near-similar levels in excitatory and inhibitory neurons. CaMKII $\beta$, while also ubiquitously expressed in dorsal horn neurons, was found at lower levels in inhibitory neurons as compared to excitatory neurons. Moreover, neuronal populations defined by expression of $\mathrm{Ca}^{2+}$-binding proteins showed marked differences in CaMKII $\alpha$ and CaMKII $\beta$ immunoreactivities.

\section{Technical considerations}

The isoform-specific CaMKII antibodies have been well characterized in the brain (Bachstetter et al. 2014; Ding et al. 2013; Erondu and Kennedy 1985; van Woerden et al. 2009), and their specificity and selectivity in the spinal cord were confirmed here using mice deficient in the respective isoform. Moreover, the extremely low immunoreactivity for either isoform in ependymal cells and microglia in the rat spinal cord further suggests that even the weak immunolabeling found in some neurons reflects specific binding. Nevertheless, it cannot be ruled out that a small proportion of neurons in this study lacked one or both of the isoforms.

The intensity of immunofluorescence may not correlate linearly with antigen density because of a number of confounding factors, including antibody cross-reactivity and variability in epitope accessibility. Thus, it is not possible to deduce, for example, that a cell exhibiting twice as strong immunofluorescence for $\mathrm{CaMKII} \alpha$ as another cell actually possesses twice as many molecules of this isoform. The present observations should, therefore, be interpreted with caution with regard to such comparisons. Nevertheless, the normalized immunofluorescence levels for a given antigen were highly consistent between tissue sections and animals, indicating that the immunolabeling, image acquisition, and analysis procedures were robust. Moreover, additional analysis by manual scoring of $\mathrm{NeuN}^{+}$ neurons yielded results consistent with those from direct intensity measurements, further supporting the utility of the latter approach. Thus, it was possible to assess general patterns of immunoreactivity levels in relation to neuronal subpopulations, and, with the caveats noted above, the expression patterns of the respective proteins. Indeed, the quantitative analysis uncovered differences in immunofluorescence of both isoforms that would have been difficult to detect with qualitative methods, including differences in CaMKII $\alpha$-to-CaMKII $\beta$ ratio.

Pax2 expression is established as a marker of inhibitory neurons in the mouse and rat dorsal horn (e.g., Cheng et al. 2004; Kardon et al. 2014; Larsson 2017). Thus, the Pax $2^{+}$ neurons in the present study were presumably inhibitory. However, in quadruple immunolabeling experiments, the proportion of Pax2 neurons in lamina III was lower than the proportion of inhibitory neurons in this region, likely because of weak Pax 2 expression in some inhibitory neurons. Thus, in these experiments, some inhibitory neurons in lamina III may have been misclassified.

\section{Excitatory and inhibitory neurons}

An unexpected finding of this study was the substantial expression of CaMKII $\alpha$ also in inhibitory neurons. In the brain, this isoform is believed to be essentially restricted to excitatory neurons (Benson et al. 1992; Sík et al. 1998). Indeed, Benson et al. (1992) reported that also GABA immunoreactive neurons in the dorsal horn lacked 

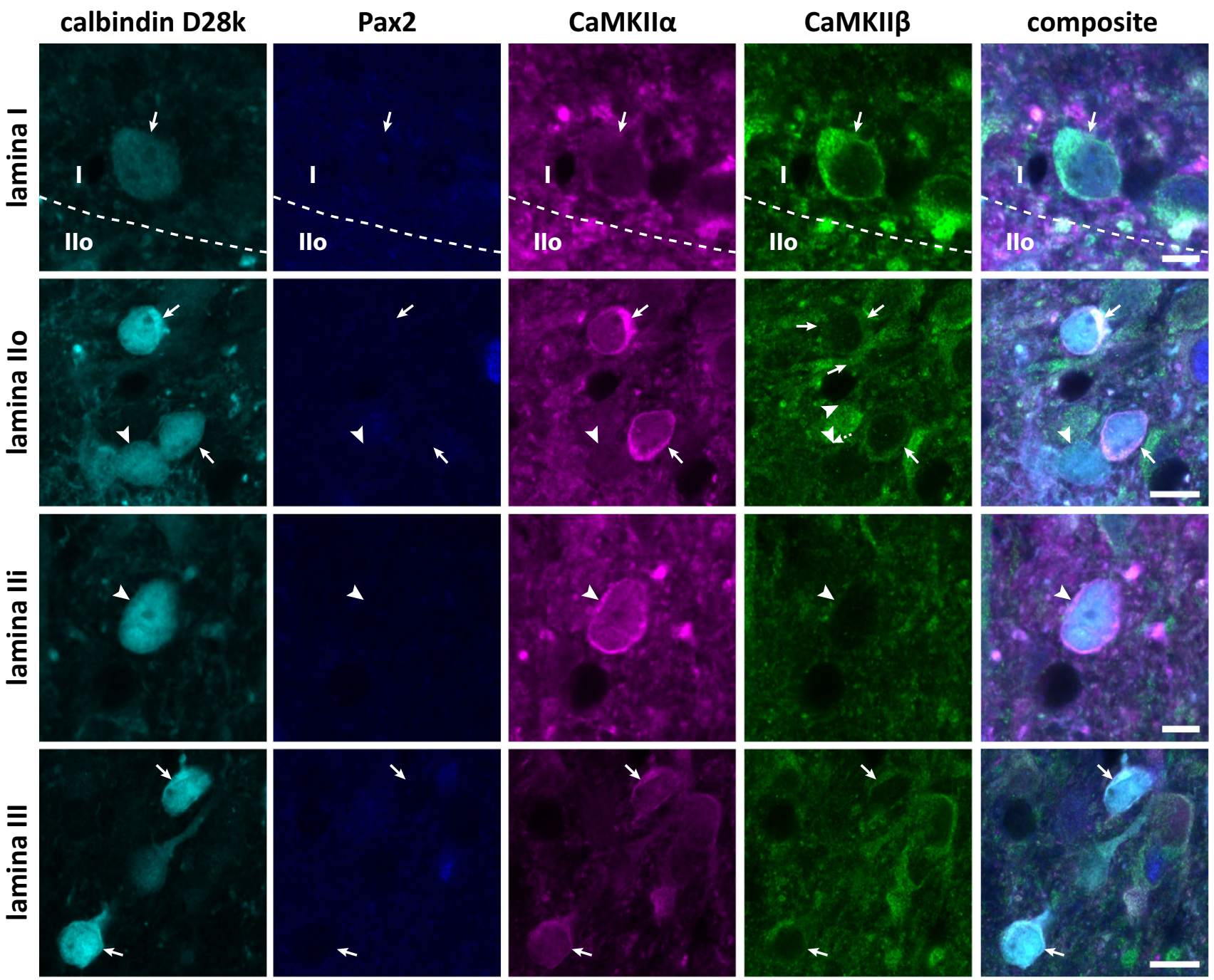

Fig. 10 CaMKII $\alpha$-LI and CaMKII $\beta$-LI in calbindin D28k neurons. Shown are examples of Pax $2^{-}$calbindin D28k neurons with variable CaMKII $\alpha$-LI and CaMKII $\beta$-LI. In lamina I, the arrow indicates a calbindin D28k neuron with moderate CaMKII $\alpha$-LI and strong CaMKII $\beta$-LI. In lamina IIo, arrowhead indicates a neuron with relatively weak CaMKII $\alpha$-LI and weak CaMKII $\beta$-LI, whereas arrows

CaMKII $\alpha$ immunoreactivity. This is difficult to reconcile with the present observations, especially as the same monoclonal antibody was used in both studies. However, Benson et al. used Wistar rats fixed with paraformaldehyde and glutaraldehyde, whereas Sprague-Dawley rats fixed without glutaraldehyde were used here; thus, strain and fixation differences could contribute to the observed differences in CaMKII $\alpha$ expression. Moreover, as GABA levels may be very low in the somata of some inhibitory neurons (Larsson 2017), it is conceivable that an actual presence of CaMKII $\alpha$ in inhibitory neurons escaped detection in the previous study (Benson et al. 1992).

CaMKII $\beta$ expression was distinctly lower in inhibitory versus excitatory neurons in the superficial dorsal horn. indicate two neurons with strong CaMKII $\alpha$-LI and moderate CaMKII $\beta$-LI. In lamina IIi, arrowhead indicates a neuron with strong CaMKII $\alpha$-LI and weak CaMKII $\beta$-LI. In lamina III, two calbindin D28k neurons moderately labeled for CaMKII $\alpha$ and CaMKII $\beta$ are indicated by arrows. Scale bars are $5 \mu \mathrm{m}$, valid for their respective set of panels

Although the distribution of CaMKII $\beta$ in the rodent spinal cord and elsewhere in the CNS is less well studied than that of CaMKII $\alpha$, the isoform is relatively widespread and expressed in some but not all GABAergic neurons (Ochiishi et al. 1994; Terashima et al. 1994; Burgin et al. 1990). The observations of Terashima et al. (1994) on the spinal distribution of CaMKII $\beta$ generally concur with the present study, although they report a somewhat stronger immunolabeling in the superficial dorsal horn compared to the rest of the gray matter. In this regard, the present results are more in line with the transcript distribution in the mouse as described in the Allen Spinal Cord Atlas (Allen Spinal Cord Atlas 2008). 
a
CaMKII $\alpha$

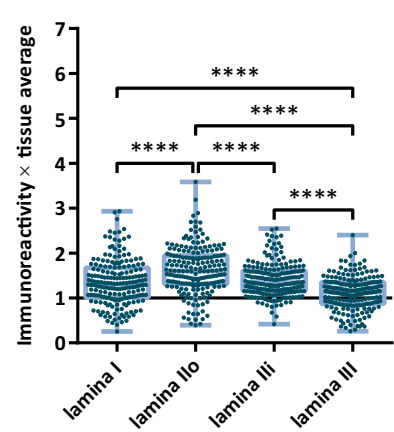

C

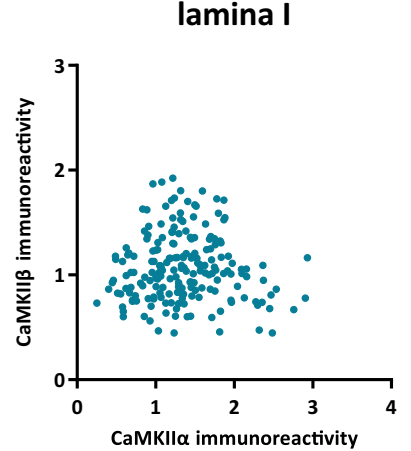

CaMKIIß

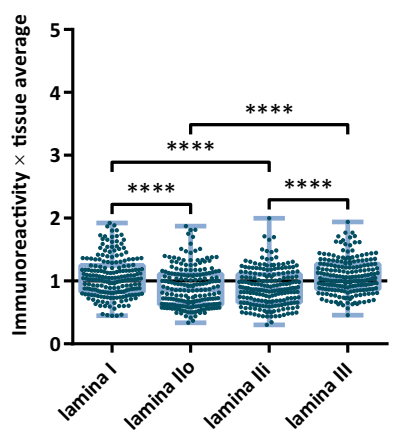

lamina llo

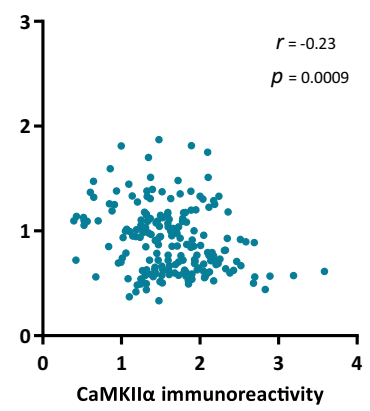

Fig. 11 Quantitative analysis of CaMKII $\alpha$-LI and CaMKII $\beta$-LI in calbindin D28k neurons. a CaMKII $\alpha$-LI and CaMKII $\beta$-LI normalized against the average intensity over laminae I-III in Pax $2^{-}$calbindin D28k neurons in laminae I-III. Solid horizontal lines indicate average tissue labeling over laminae I-III. b ratio of normalized CaMKII $\alpha$-LI over normalized CaMKII $\beta$-LI in Pax $2^{-}$calbindin D28k neurons in

\section{Parvalbumin neurons}

Although some parvalbumin neurons in the rat dorsal horn are excitatory (Antal et al. 1991; Laing et al. 1994), a higher-than-expected proportion of parvalbumin neurons lacking Pax2, and thus classified as presumed excitatory, was found in lamina III. However, as noted above, some of these may have been misclassified because of weak Pax2 expression. Nevertheless, a distinct pattern with respect to CaMKII isoform expression was observed in presumed excitatory parvalbumin neurons. Such neurons in lamina IIi showed strong expression of CaMKII $\alpha$ and weak expression of CaMKII $\beta$, whereas presumed excitatory neurons in lamina III showed a lower expression of CaMKII $\alpha$ but a considerably higher expression of CaMKII $\beta$. Inhibitory parvalbumin lamina IIi neurons showed moderate levels of CaMKII $\alpha$ and low levels of CaMKII $\beta$, whereas inhibitory lamina III parvalbumin neurons showed low levels of both isoforms. Thus, it appears possible to delineate several populations of parvalbumin neurons in the superficial dorsal horn based on transmitter phenotype, location, and b

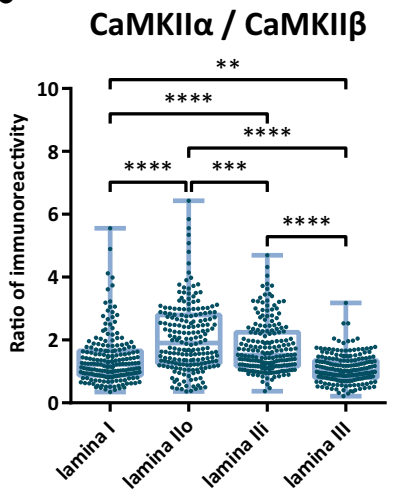

lamina Ili

lamina III
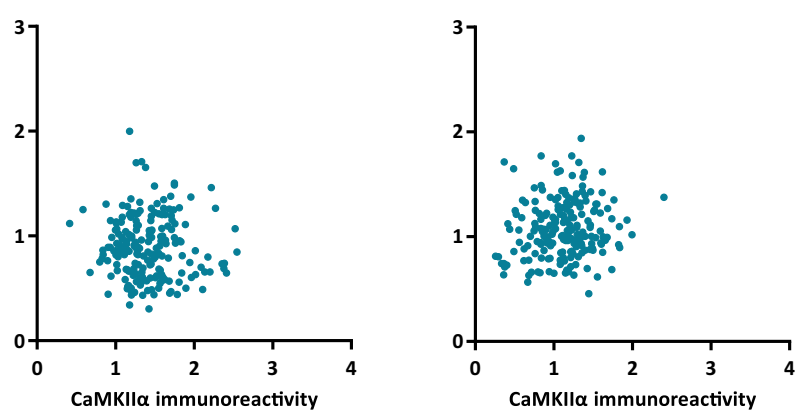

laminae I-III. $* * p<0.01 ; * * * p<0.001$; $* * * p<0.0001$; one-way ANOVA followed by Tukey's post hoc test. c Scatterplots of normalized CaMKII $\beta$-LI versus normalized CaMKII $\alpha$-LI in each lamina. Correlations were assessed using Spearman's correlation. A weak negative correlation was found in lamina IIo, but not in other laminae

CaMKII isoform expression. The relatively low expression of CaMKII $\alpha$ and CaMKII $\beta$ in inhibitory parvalbumin neurons suggests that these cells are not very susceptible to CaMKII-mediated plasticity.

\section{Calretinin neurons}

About $8 \%$ of calretinin neurons in laminae I-II were $\mathrm{Pax}^{+}$, indicating that a small proportion of calretinin neurons in the rat dorsal horn is inhibitory, as is the case in the mouse (Smith et al. 2015; Huang et al. 2010). In lamina II, such neurons showed strong CaMKII $\alpha$ and weak CaMKII $\beta$ expression. Furthermore, whereas most excitatory calretinin neurons showed moderate levels of both CaMKII $\alpha$ and CaMKII $\beta$, a distinct subpopulation of excitatory calretinin neurons in lamina II exhibited a high CaMKII $\alpha$-to-CaMKII $\beta$ ratio, similar to inhibitory calretinin neurons. Further studies are needed to determine whether these populations overlap with functionally identified subpopulations of calretinin neuron (Smith et al. 2015). 
a

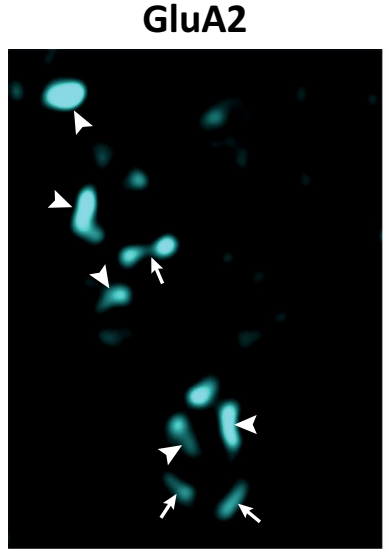

CaMKII $\alpha$

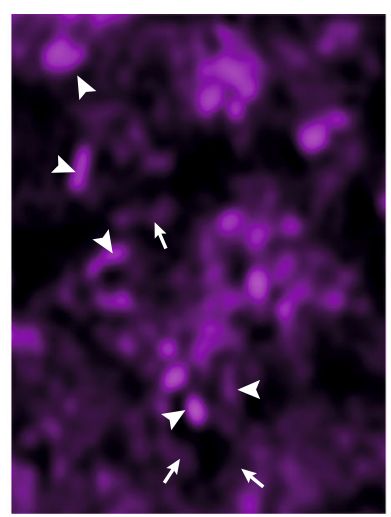

CaMKII $\beta$

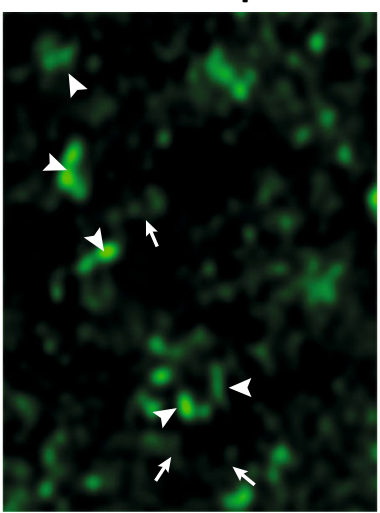

composite

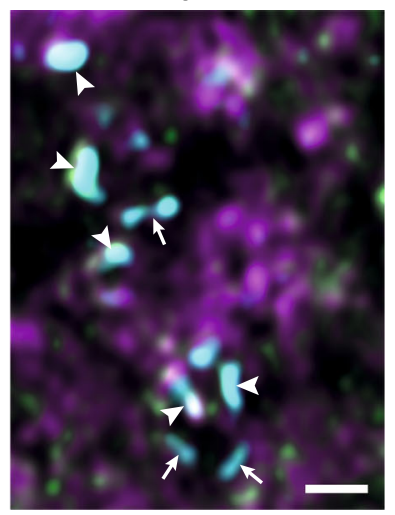

b

lamina I

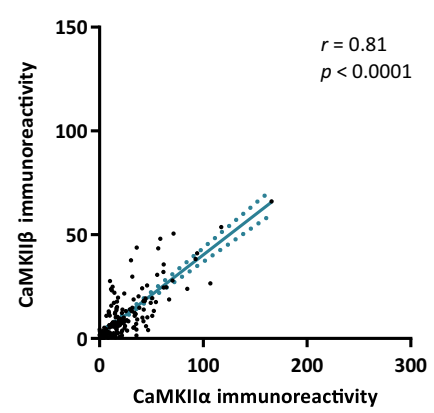

lamina Ilo

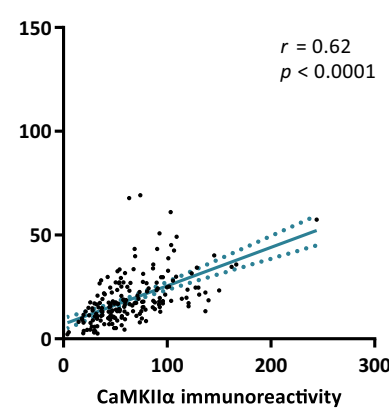

Fig. 12 CaMKII $\alpha$-LI and CaMKII $\beta$-LI after pepsin-mediated antigen retrieval to reveal postsynaptic proteins. a region of lamina IIi in a spinal cord section immunolabeled for the AMPA receptor subunit GluA2, CaMKII $\alpha$, and CaMKII $\beta$. GluA2 immunolabeling localizes to puncta that presumably correspond to excitatory synapses. CaMKII $\alpha$ and CaMKII $\beta$ immunolabeling often co-localize in GluA2 $2^{+}$puncta at variable levels, although substantial immunolabeling is found also outside such puncta. Arrowheads indicate $\mathrm{GluA}^{+}$puncta that colocalize with substantial CaMKII $\alpha$-LI and CaMKII $\beta$-LI, whereas

\section{Calbindin D28k neurons}

Calbindin D28k neurons in lamina IIo were somewhat enriched in CaMKII $\alpha$ compared to other laminae. Moreover, calbindin D28k neurons in lamina III had higher CaMKII $\alpha$ levels than unclassified neurons in this lamina. By contrast, CaMKII $\beta$ expression in calbindin D28k neurons was relatively low in all laminae. Indeed, calbindin D28k neurons in laminae IIo and III had substantially higher CaMKII $\alpha$-to-CaMKII $\beta$ ratio than other excitatory neurons in these laminae. Thus, although calbindin D28k neurons probably constitute a functionally heterogeneous population (Todd 2017), they may exhibit some degree of functional specificity with regard to CaMKII-mediated processes.

lamina Ili

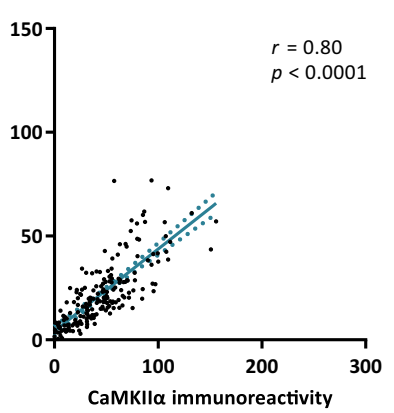

lamina III

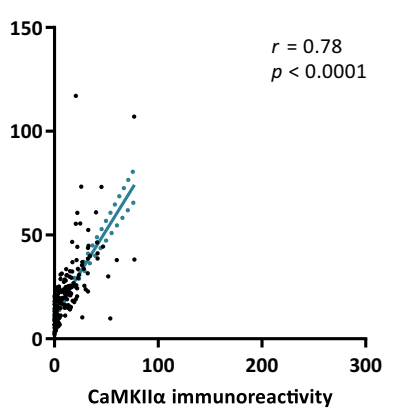

arrows indicate $\mathrm{GluA}^{+}$puncta with weak or no labeling for CaMKII $\alpha$ or CaMKII $\beta$. The micrographs are from a single deconvolved optical section obtained using a $63 \times / 1.4$ objective. Scale bar, $1 \mu \mathrm{m}$ valid for all panels. b Scatterplots of CaMKII $\beta$-LI versus CaMKII $\alpha$-LI in GluA2 ${ }^{+}$puncta in each lamina. Note the low levels of CaMKII $\alpha$-LI in many puncta in lamina III. Correlations were assessed using Spearman's correlation. Solid and dashed lines indicate linear regression with $95 \%$ confidence intervals. Strong positive correlations were found in all laminae

\section{Postsynaptic CaMKII}

The levels of CaMKII $\alpha$-LI and CaMKII $\beta$-LI were positively correlated at $\mathrm{GluA}^{+}$puncta [presumably corresponding to excitatory synapses (Polgár et al. 2008)] in all superficial laminae in pepsin-treated spinal cord sections. This was in contrast to the soma, which, in most neuronal populations, showed little or no correlation between CaMKII $\alpha$-LI and CaMKII $\beta$-LI. CaMKII $\beta$ is required for targeting the holoenzyme to dendritic spines (Borgesius et al. 2011); therefore, even in cells with low CaMKII $\beta$ expression, postsynaptic pools of CaMKII may be relatively enriched in this isoform, thereby increasing postsynaptic co-variability of CaMKII $\alpha$ and CaMKII $\beta$ levels. At the same time, as many inhibitory (and some excitatory) neurons in the dorsal horn exhibit few spines (Cordero- 
Erausquin et al. 2009; Grudt and Perl 2002; Todd and Lewis 1986), synaptic targeting of CaMKII in these neurons may be less dependent on CaMKII $\beta$.

Many $\mathrm{GluA}_{2}{ }^{+}$puncta showed weak or undetectable immunoreactivity for either CaMKII isoform. It is possible that this reflected a genuine scarcity of CaMKII at these synapses, but it could conceivably also be partly attributed to differential sensitivity to pepsin-mediated degradation of GluA2 and CaMKII, such that CaMKII was largely degraded at some synapses that retained most GluA2 protein.

\section{Functional and technical implications}

In addition to its key role in the early phase long-term potentiation and similar phenomena, CaMKII has been implicated in diverse neuronal processes that may be subject to plasticity, including presynaptic transmitter release, membrane excitability, and excitation-transcription coupling (Hund et al. 2010; Wang 2008; Coultrap and Bayer 2012; Ma et al. 2015; Hell 2014; Lisman et al. 2012). Differences in isoform composition of CaMKII holoenzymes both in the postsynaptic density as well as in the soma and other extrasynaptic compartments may, therefore, impact different forms of neuronal plasticity. Many neurons, including most inhibitory neurons, weakly expressed CaMKII $\beta$. As this isoform is more sensitive to $\mathrm{Ca}^{2+}$ and saturates at lower $\mathrm{Ca}^{2+}$ spike frequencies than CaMKII $\alpha$, low expression of CaMKII $\beta$ will shift the response curve towards higher $\mathrm{Ca}^{2+}$ concentrations and frequencies (Brocke et al. 1999; De Koninck and Schulman 1998); therefore, for instance, neurons with low cytosolic CaMKII $\beta$ levels may require stronger activation to effect mechanisms relying on cytosolic CaMKII, such as excitation-transcription coupling (Ma et al. 2015).

Most parvalbumin neurons as well as many other neurons showed weak labeling for both CaMKII $\alpha$ and CaMKII $\beta$. This could reflect a lower propensity for plasticity, but it is also possible that other CaMKII isoforms or CaMKII-independent mechanisms may contribute to plasticity in such neurons. Regardless, the substantial expression of CaMKII $\alpha$ in many inhibitory neurons suggests that these may also be susceptible to neuronal plasticity dependent on this isoform.

Conditional genetic tools that rely on the Camk2a promoter to direct selective protein expression to excitatory neurons are widely used, most commonly in the context of the forebrain but also in the spinal dorsal horn ( $\mathrm{Lu}$ et al. 2015; Simonetti et al. 2013). However, the expression of CaMKII $\alpha$ in both excitatory and inhibitory neurons in the superficial dorsal horn suggests that caution should be exercised when using such tools, especially in the dorsal horn, where they may not be valid for selective targeting of excitatory neurons.

\section{Conclusions}

This mapping of CaMKII $\alpha$ and CaMKII $\beta$ in the rat superficial dorsal horn revealed extensive co-localization in all or nearly all excitatory and inhibitory neurons. Moreover, different populations of dorsal horn neuron defined by transmitter phenotype, calcium-binding proteins, and location differed in their pattern of expression of each isoform. This implicates that whereas CaMKII-mediated signaling and plasticity may be ubiquitous in the superficial dorsal horn, neuronal populations exhibit differences in the characteristics of such mechanisms.

Acknowledgements This work was supported by the Linköping Centre for Systems Neurobiology, the Medical Faculty at Linköping University, and the Royal Academy of Sciences.

\section{Compliance with ethical standards}

Conflict of interest The author declares that he has no conflict of interest.

Open Access This article is distributed under the terms of the Creative Commons Attribution 4.0 International License (http://crea tivecommons.org/licenses/by/4.0/), which permits unrestricted use, distribution, and reproduction in any medium, provided you give appropriate credit to the original author(s) and the source, provide a link to the Creative Commons license, and indicate if changes were made.

\section{References}

Albuquerque C, Lee CJ, Jackson AC, MacDermott AB (1999) Subpopulations of GABAergic and non-GABAergic rat dorsal horn neurons express $\mathrm{Ca}^{2+}$-permeable AMPA receptors. Eur J Neurosci 11(8):2758-2766

Allen Spinal Cord Atlas (2008). http://mousespinal.brain-map.org. Accessed 11 Apr 2016

Antal M, Freund TF, Polgár E (1990) Calcium-binding proteins, parvalbumin- and calbindin-D 28k-immunoreactive neurons in the rat spinal cord and dorsal root ganglia: a light and electron microscopic study. J Comp Neurol 295(3):467-484. https://doi. org/10.1002/cne. 902950310

Antal M, Polgár E, Chalmers J, Minson JB, Llewellyn-Smith I, Heizmann CW, Somogyi P (1991) Different populations of parvalbumin- and calbindin-D28k-immunoreactive neurons contain GABA and accumulate ${ }^{3} \mathrm{H}$-D-aspartate in the dorsal horn of the rat spinal cord. J Comp Neurol 314(1):114-124. https://doi. org/10.1002/cne.903140111

Bachstetter AD, Webster SJ, Tu T, Goulding DS, Haiech J, Watterson DM, Van Eldik LJ (2014) Generation and behavior characterization of CaMKII $\beta$ knockout mice. PLoS one 9(8):e105191. https://doi.org/10.1371/journal.pone.0105191

Benson DL, Isackson PJ, Gall CM, Jones EG (1992) Contrasting patterns in the localization of glutamic acid decarboxylase and $\mathrm{Ca}^{2+} /$ calmodulin protein kinase gene expression in the rat 
central nervous system. Neuroscience 46(4):825-849. https://doi. org/10.1016/0306-4522(92)90188-8

Borgesius NZ, van Woerden GM, Buitendijk GH, Keijzer N, Jaarsma D, Hoogenraad CC, Elgersma Y (2011) ßCaMKII plays a nonenzymatic role in hippocampal synaptic plasticity and learning by targeting $\alpha \mathrm{CaMKII}$ to synapses. J Neurosci 31(28):10141-10148. https://doi.org/10.1523/JNEUROSCI. 5105-10.2011

Brocke L, Chiang LW, Wagner PD, Schulman H (1999) Functional implications of the subunit composition of neuronal CaM kinase II. J Biol Chem 274(32):22713-22722

Brüggemann I, Schulz S, Wiborny D, Höllt V (2000) Colocalization of the $\mu$-opioid receptor and calcium/calmodulin-dependent kinase II in distinct pain-processing brain regions. Brain Res Mol Brain Res 85(1-2):239-250

Burgin K, Waxham M, Rickling S, Westgate S, Mobley W, Kelly P (1990) In situ hybridization histochemistry of $\mathrm{Ca}^{2+} /$ calmodulindependent protein kinase in developing rat brain. J Neurosci 10(6): 1788-1798

Cheng L, Arata A, Mizuguchi R, Qian Y, Karunaratne A, Gray PA, Arata S, Shirasawa S, Bouchard M, Luo P, Chen CL, Busslinger M, Goulding M, Onimaru H, Ma Q (2004) Tlx3 and Tlx1 are post-mitotic selector genes determining glutamatergic over GABAergic cell fates. Nat Neurosci 7(5):510-517. https://doi. org/10.1038/nn1221

Cordero-Erausquin M, Allard S, Dolique T, Bachand K, Ribeiro-daSilva A, De Koninck Y (2009) Dorsal horn neurons presynaptic to lamina I spinoparabrachial neurons revealed by transynaptic labeling. J Comp Neurol 517(5):601-615. https://doi.org/10. 1002/cne.22179

Coultrap SJ, Bayer KU (2012) CaMKII regulation in information processing and storage. Trends Neurosci 35(10):607-618. https://doi.org/10.1016/j.tins.2012.05.003

De Koninck P, Schulman H (1998) Sensitivity of CaM kinase II to the frequency of $\mathrm{Ca}^{2+}$ oscillations. Science 279(5348):227-230

Ding J-D, Kennedy MB, Weinberg RJ (2013) Subcellular organization of CaMKII in rat hippocampal pyramidal neurons. J Comp Neurol 521(15):3570-3583. https://doi.org/10.1002/cne.23372

Elgersma Y, Fedorov NB, Ikonen S, Choi ES, Elgersma M, Carvalho OM, Giese KP, Silva AJ (2002) Inhibitory autophosphorylation of CaMKII controls PSD association, plasticity, and learning. Neuron 36(3):493-505. https://doi.org/10.1016/S08966273(02)01007-3

Erondu NE, Kennedy MB (1985) Regional distribution of type II $\mathrm{Ca}^{2+} /$ calmodulin-dependent protein kinase in rat brain. $\mathrm{J}$ Neurosci 5(12):3270-3277

Fang L, Wu J, Lin Q, Willis WD (2002) Calcium-calmodulindependent protein kinase II contributes to spinal cord central sensitization. J Neurosci 22(10):4196-4204

Gao Z, van Woerden GM, Elgersma Y, De Zeeuw CI, Hoebeek FE (2014) Distinct roles of $\alpha$ - and $\beta$ CaMKII in controlling longterm potentiation of GABAA-receptor mediated transmission in murine Purkinje cells. Front Cell Neurosci 8:16. https://doi.org/ 10.3389/fncel.2014.00016

Grudt TJ, Perl ER (2002) Correlations between neuronal morphology and electrophysiological features in the rodent superficial dorsal horn. J Physiol 540(Pt 1):189-207

Hell JW (2014) CaMKII: claiming center stage in postsynaptic function and organization. Neuron 81(2):249-265. https://doi. org/10.1016/j.neuron.2013.12.024

Huang J, Chen J, Wang W, Wang W, Koshimizu Y, Wei YY, Kaneko T, Li YQ, Wu SX (2010) Neurochemical properties of enkephalinergic neurons in lumbar spinal dorsal horn revealed by preproenkephalin-green fluorescent protein transgenic mice. J Neurochem 113(6):1555-1564. https://doi.org/10.1111/j.14714159.2010.06715.x
Hund TJ, Koval OM, Li J, Wright PJ, Qian L, Snyder JS, Gudmundsson H, Kline CF, Davidson NP, Cardona N, Rasband MN, Anderson ME, Mohler PJ (2010) A $\beta I V$-spectrin/CaMKII signaling complex is essential for membrane excitability in mice. J Clin Investig 120(10):3508-3519. https://doi.org/10.1172/ JCI43621

Jones TL, Sorkin LS (2005) Activated PKA and PKC, but not CaMKIIa, are required for AMPA/Kainate-mediated pain behavior in the thermal stimulus model. Pain 117(3):259-270. https:// doi.org/10.1016/j.pain.2005.06.003

Kardon AP, Polgar E, Hachisuka J, Snyder LM, Cameron D, Savage S, Cai X, Karnup S, Fan CR, Hemenway GM, Bernard CS, Schwartz ES, Nagase H, Schwarzer C, Watanabe M, Furuta T, Kaneko T, Koerber HR, Todd AJ, Ross SE (2014) Dynorphin acts as a neuromodulator to inhibit itch in the dorsal horn of the spinal cord. Neuron 82(3):573-586. https://doi.org/10.1016/j. neuron.2014.02.046

Laing I, Todd AJ, Heizmann CW, Schmidt HH (1994) Subpopulations of GABAergic neurons in laminae I-III of rat spinal dorsal horn defined by coexistence with classical transmitters, peptides, nitric oxide synthase or parvalbumin. Neuroscience 61(1):123-132

Larsson M (2009) Ionotropic glutamate receptors in spinal nociceptive processing. Mol Neurobiol 40(3):260-288. https://doi.org/ 10.1007/s12035-009-8086-8

Larsson M (2017) Pax2 is persistently expressed by GABAergic neurons throughout the adult rat dorsal horn. Neurosci Lett 638:96-101. https://doi.org/10.1016/j.neulet.2016.12.015

Larsson M, Broman J (2006) Pathway-specific bidirectional regulation of $\mathrm{Ca}^{2+} /$ calmodulin-dependent protein kinase II at spinal nociceptive synapses after acute noxious stimulation. J Neurosci 26(16):4198-4205. https://doi.org/10.1523/JNEUROSCI.035206.2006

Larsson M, Broman J (2008) Translocation of GluR1-containing AMPA receptors to a spinal nociceptive synapse during acute noxious stimulation. J Neurosci 28(28):7084-7090. https://doi. org/10.1523/JNEUROSCI.5749-07.2008

Larsson M, Broman J (2011) Synaptic plasticity and pain: role of ionotropic glutamate receptors. Neuroscientist 17:256-273. https://doi.org/10.1177/1073858409349913

Larsson M, Morland C, Poblete-Naredo I, Biber J, Danbolt NC, Gundersen V (2011) The sodium-dependent inorganic phosphate transporter SLC34A1 (NaPi-IIa) is not localized in the mouse brain: a case of tissue-specific antigenic cross-reactivity. J Histochem Cytochem 59(9):807-812. https://doi.org/10.1369/ 0022155411411713

Larsson M, Agalave N, Watanabe M, Svensson CI (2013) Distribution of transmembrane AMPA receptor regulatory protein (TARP) isoforms in the rat spinal cord. Neuroscience 248:180-193. https://doi.org/10.1016/j.neuroscience.2013.05. 060

Lisman J, Yasuda R, Raghavachari S (2012) Mechanisms of CaMKII action in long-term potentiation. Nat Rev Neurosci 13(3):169-182. https://doi.org/10.1038/nrn3192

Liu XB, Murray KD (2012) Neuronal excitability and calcium/calmodulin-dependent protein kinase type II: location, location, location. Epilepsia 53(Suppl 1):45-52. https://doi.org/ 10.1111/j.1528-1167.2012.03474.x

Lu J, Luo C, Bali KK, Xie RG, Mains RE, Eipper BA, Kuner R (2015) A role for Kalirin-7 in nociceptive sensitization via activity-dependent modulation of spinal synapses. Nat Commun 6:6820. https://doi.org/10.1038/ncomms7820

Ma H, Li B, Tsien RW (2015) Distinct roles of multiple isoforms of CaMKII in signaling to the nucleus. Biochim Biophys Acta 1853(9):1953-1957. https://doi.org/10.1016/j.bbamcr.2015.02. 008 
Manning CF, Bundros AM, Trimmer JS (2012) Benefits and pitfalls of secondary antibodies: why choosing the right secondary is of primary importance. PloS one 7(6):e38313. https://doi.org/10. 1371/journal.pone.0038313

Nagy GG, Al-Ayyan M, Andrew D, Fukaya M, Watanabe M, Todd AJ (2004) Widespread expression of the AMPA receptor GluR2 subunit at glutamatergic synapses in the rat spinal cord and phosphorylation of GluR1 in response to noxious stimulation revealed with an antigen-unmasking method. J Neurosci 24(25):5766-5777. https://doi.org/10.1523/jneurosci.1237-04. 2004

Ochiishi T, Terashima T, Yamauchi T (1994) Specific distribution of $\mathrm{Ca}^{2+} /$ calmodulin-dependent protein kinase II alpha and beta isoforms in some structures of the rat forebrain. Brain Res 659(1-2):179-193

Polgár E, Hughes DI, Riddell JS, Maxwell DJ, Puskar Z, Todd AJ (2003) Selective loss of spinal GABAergic or glycinergic neurons is not necessary for development of thermal hyperalgesia in the chronic constriction injury model of neuropathic pain. Pain 104(1-2):229-239

Polgár E, Watanabe M, Hartmann B, Grant SG, Todd AJ (2008) Expression of AMPA receptor subunits at synapses in laminae IIII of the rodent spinal dorsal horn. Mol Pain 4:5. https://doi.org/ 10.1186/1744-8069-4-5

Ren K, Ruda MA (1994) A comparative study of the calcium-binding proteins calbindin-D28K, calretinin, calmodulin and parvalbumin in the rat spinal cord. Brain Res Brain Res Rev 19(2):163-179

Shen K, Meyer T (1999) Dynamic control of CaMKII translocation and localization in hippocampal neurons by NMDA receptor stimulation. Science 284(5411):162-166

Shen K, Teruel MN, Subramanian K, Meyer T (1998) CaMKII $\beta$ functions as an F-actin targeting module that localizes CaMKII $\alpha /$ $\beta$ heterooligomers to dendritic spines. Neuron 21(3):593-606

Sík A, Hajos N, Gulacsi A, Mody I, Freund TF (1998) The absence of a major $\mathrm{Ca}^{2+}$ signaling pathway in GABAergic neurons of the hippocampus. Proc Natl Acad Sci USA 95(6):3245-3250

Simonetti M, Hagenston AM, Vardeh D, Freitag HE, Mauceri D, Lu J, Satagopam VP, Schneider R, Costigan M, Bading H, Kuner R (2013) Nuclear calcium signaling in spinal neurons drives a genomic program required for persistent inflammatory pain. Neuron 77(1):43-57. https://doi.org/10.1016/j.neuron.2012.10. 037

Smith KM, Boyle KA, Madden JF, Dickinson SA, Jobling P, Callister RJ, Hughes DI, Graham BA (2015) Functional heterogeneity of calretinin-expressing neurons in the mouse superficial dorsal horn: implications for spinal pain processing. J Physiol 593(19):4319-4339. https://doi.org/10.1113/JP270855

Terashima T, Ochiishi T, Yamauchi T (1994) Immunohistochemical detection of calcium/calmodulin-dependent protein kinase II in the spinal cord of the rat and monkey with special reference to the corticospinal tract. J Comp Neurol 340(4):469-479. https:// doi.org/10.1002/cne.903400403

Todd AJ (2017) Identifying functional populations among the interneurons in laminae I-III of the spinal dorsal horn. Mol Pain 13:1744806917693003. https://doi.org/10.1177/ 1744806917693003

Todd AJ, Lewis SG (1986) The morphology of Golgi-stained neurons in lamina II of the rat spinal cord. J Anat 149:113-119

Todd AJ, Sullivan AC (1990) Light microscope study of the coexistence of GABA-like and glycine-like immunoreactivities in the spinal cord of the rat. J Comp Neurol 296(3):496-505. https://doi.org/10.1002/cne.902960312

Todd AJ, Spike RC, Polgár E (1998) A quantitative study of neurons which express neurokinin-1 or somatostatin sst2a receptor in rat spinal dorsal horn. Neuroscience 85(2):459-473. https://doi.org/ 10.1016/S0306-4522(97)00669-6

van Woerden GM, Hoebeek FE, Gao Z, Nagaraja RY, Hoogenraad CC, Kushner SA, Hansel C, De Zeeuw CI, Elgersma Y (2009) betaCaMKII controls the direction of plasticity at parallel fiberPurkinje cell synapses. Nat Neurosci 12(7):823-825. https://doi. org/10.1038/nn.2329

Wang Z-W (2008) Regulation of synaptic transmission by presynaptic CaMKII and BK channels. Mol Neurobiol 38(2):153-166. https://doi.org/10.1007/s12035-008-8039-7

Watanabe M, Fukaya M, Sakimura K, Manabe T, Mishina M, Inoue Y (1998) Selective scarcity of NMDA receptor channel subunits in the stratum lucidum (mossy fibre-recipient layer) of the mouse hippocampal CA3 subfield. Eur J Neurosci 10(2):478-487

Yang HW, Hu XD, Zhang HM, Xin WJ, Li MT, Zhang T, Zhou LJ, Liu XG (2004) Roles of CaMKII, PKA, and PKC in the induction and maintenance of LTP of C-fiber-evoked field potentials in rat spinal dorsal horn. $\mathbf{J}$ Neurophysiol 91(3):1122-1133. https://doi.org/10.1152/jn.00735.2003

Zeitz KP, Giese KP, Silva AJ, Basbaum AI (2004) The contribution of autophosphorylated a-calcium-calmodulin kinase II to injuryinduced persistent pain. Neuroscience 128(4):889-898. https:// doi.org/10.1016/j.neuroscience.2004.07.029 